\title{
One-carbon metabolism in psychiatric illness
}

\author{
C. Sugden \\ Centre for Nutrition and Food Safety, School of Biomedical and Molecular Sciences, \\ University of Surrey, Guildford, Surrey GU2 7XH, UK
}

\begin{abstract}
The cost of psychiatric illness to the UK economy was recently estimated at $£ 77$ billion annually. Despite years of research no firm aetiological explanation exists, and with no physiological or biochemical markers diagnosis is made entirely on a behavioural basis. All current pharmacological therapies are associated with serious long-term side effects. Substantial evidence supports the involvement of one-carbon cycle dysregulation in psychiatric illness, but this is not currently used as a basis for diagnosis or treatment. The present paper reviews the evidence for one-carbon cycle dysregulation in schizophrenic, bipolar, depressed and autistic patients. Also presented are novel findings from the field of epigenetics, which demonstrate how the one-carbon cycle-derived methyl donor $S$-adenosylmethionine influences the expression of key genes in the brain affecting memory, learning, cognition and behaviour, genes whose expression is reduced to varying degrees in these patient groups. Clinical evidence that nutritional supplements can rectify one-carbon cycle activity, and restore normal gene expression, suggests a novel approach to the development of biochemical tests and simple, non-harmful treatments for some psychiatric patients. Conversely, evidence from animal studies highlights the dangers of exposing the unborn fetus to very high dietary levels of folic acid, a one-carbon cycle cofactor. Fetal adaptations to a high-folate environment may interfere with folate metabolism postnatally, with serious consequences for the epigenetic regulation of gene expression. The public health implications of these diverse scenarios indicate an urgent need for further research in this field.
\end{abstract}

\section{Methylation: Epigenetics: Psychiatric illness: Autism: One-carbon metabolism: $S$-adenosylmethionine}

\section{Introduction}

One in four individuals experience an episode of psychiatric illness in their lifetime; the worldwide incidence of schizophrenia is $1 \%$ and that of bipolar disorder (BPD) is $1-2 \%$. Due to the social stigma associated with psychiatric illness, and the side effects of neuroleptic treatments, the consequences for individuals can be devastating and lifelong. Despite years of research, no firm causal evidence exists, although the actions of symptom-modulating drugs have generated various hypotheses. Psychiatric diagnoses say nothing about aetiology, and are incapable of predicting the course of the illness or which treatments will be effective. Implementing drug therapy is thus a process of trial and error (Bentall, 2003).

Little attention is currently paid in psychiatry to the influence of nutrition on mental health, beyond concern that psychotropic medication is associated with weight gain, which may increase CVD risk in patients.

The present paper explores the evidence that poor B vitamin or folate intake and/or disordered metabolism influences mental states by disrupting cellular methylation status, altering the expression and activity of key genes involved in brain development and function, and that nutritional therapy can improve or restore mental health in some patients.

\footnotetext{
Abbreviations: BHMT, betaine-homocysteine methyltransferase; BPD, bipolar disorder; CDP, cytidine diphosphate; CNS, central nervous system; COMT, catechol- $O$-methyltransferase; $\mathrm{CPK}_{\mathrm{MM}}$, muscle-derived serum creatine phosphokinase; CSF, cerebral spinal fluid; DBPC, double-blind placebo-controlled; Dnmt, DNA methyltransferase; DSM, Diagnostic and Statistical Manual; GABA, $\gamma$-aminobutyric acid; GAD, glutamic acid decarboxylase; GNMT, glycine $N$-methyltransferase; Hcy, homocysteine; HRM, heterozygous reeler mouse; LCPUFA, long-chain PUFA; MS, methionine synthase; MTHF, methylenetetrahydrofolate; NMDA, $N$-methyl-D-aspartate; NTD, neural tube defect; OR, odds ratio; PC, phosphatidylcholine; PE, phosphatidylethanolamine; PEMT, phosphatidylethanolamine methyltransferase; PG, prostaglandin; PLA2, phospholipase A2; PLM, phospholipid methylation; SAH, S-adenosylhomocysteine; SAM, S-adenosylmethionine; SANS, Scale for the Assessment of Negative Symptoms; SHMT, serine hydroxymethyltransferase; SNP, single nucleotide polymorphism; WTM, wild-type mice.
}

Corresponding author: C. Sugden, email csugden@mscnm.wanadoo.co.uk 


\section{Methods}

A literature search of the databases ScienceDirect, HighWire and Medline was conducted, using combinations of the search terms 'schizophrenia', 'depression', 'bipolar disorder' and 'autism' with each of the metabolites and enzymes of the one-carbon cycle. As the hypothesis developed, new search terms were added, including 'methyltransferase', 'methylation', and 'reelin'. Papers were reviewed and relevant cited papers and books were also obtained. Recent studies were included if they were adequately controlled with sufficient numbers of subjects. Older studies not meeting these criteria were included if they tested associations that have not been re-examined more recently. The results of these searches are assembled in three sections. The first explores associations between dietand/or genotype-induced disordered one-carbon metabolism and psychiatric illnesses. The second explains how methylation impacts on phospholipid structure and function, and how disordered one-carbon metabolism could produce the alterations in fatty acid profiles found in psychiatric patients. The third introduces the field of epigenetics, detailing animal and human studies that indicate mechanisms whereby pre- and postnatal environmental influences such as diet can influence gene expression, central nervous system (CNS) development and function, and psychiatric symptoms.

\section{The one-carbon cycle and psychiatric illness}

\section{One-carbon metabolism}

Fig. 1 illustrates the interaction between folate metabolism, the methionine cycle, and transmethylation reactions, collectively known as one-carbon metabolism. Vitamin $\mathrm{B}_{6}$-dependent serine hydroxymethyltransferase (SHMT) catalyses the conversion of serine to glycine, producing 5,10-methylenetetrahydrofolate (MTHF) from tetrahydrofolate. 5,10-MTHF can then be used: to synthesise purines; as the substrate for $\mathrm{B}_{2}$-dependent MTHF reductase producing 5-MTHF; as a substrate for thymidine synthase generating deoxythymidine-monophosphate from deoxyuridylate, the limiting reaction in DNA biosynthesis. 5-MTHF is the methyl-donor for the re-methylation of homocysteine (Hcy) by cobalamin-dependent methionine synthase (MS), yielding methionine. Hepatic tissues have an alternate pathway for Hcy re-methylation via $\mathrm{Zn}$-dependent betainehomocysteine methyltransferase (BHMT) where betaine serves as the methyl-donor. Methionine is converted to $S$ adenosylmethionine (SAM) by methionine adenosyltransferase. SAM is the methyl-donor in over 100 transmethylation reactions involving DNA, proteins, neurotransmitters, hormones and phospholipids. Donation of the methyl group leads to the formation of $S$-adenosylhomocysteine (SAH), which is hydrolysed to Hcy and adenosine by SAH hydrolase. The equilibrium of this reaction favours SAH production, hence Hcy and adenosine must be efficiently removed. In addition to re-methylation, Hcy is also metabolised via the trans-sulfuration pathway, where it combines with serine to form cysteine by two vitamin $\mathrm{B}_{6}$-dependent enzymes, cystathionine $\beta$-synthase and cystathionine $\gamma$-lyase.

\section{Methylation regulation}

SAM is responsible for all methylation reactions. Conversely, SAH inhibits such reactions by effectively competing with SAM for methyltransferase binding. The SAM:SAH ratio thus describes the 'cellular methylation potential'. The major regulators of methylation potential are glycine $N$-methyltransferase (GNMT) and MTHF reductase. GNMT binds 5-MTHF and high 5-MTHF levels inhibit its

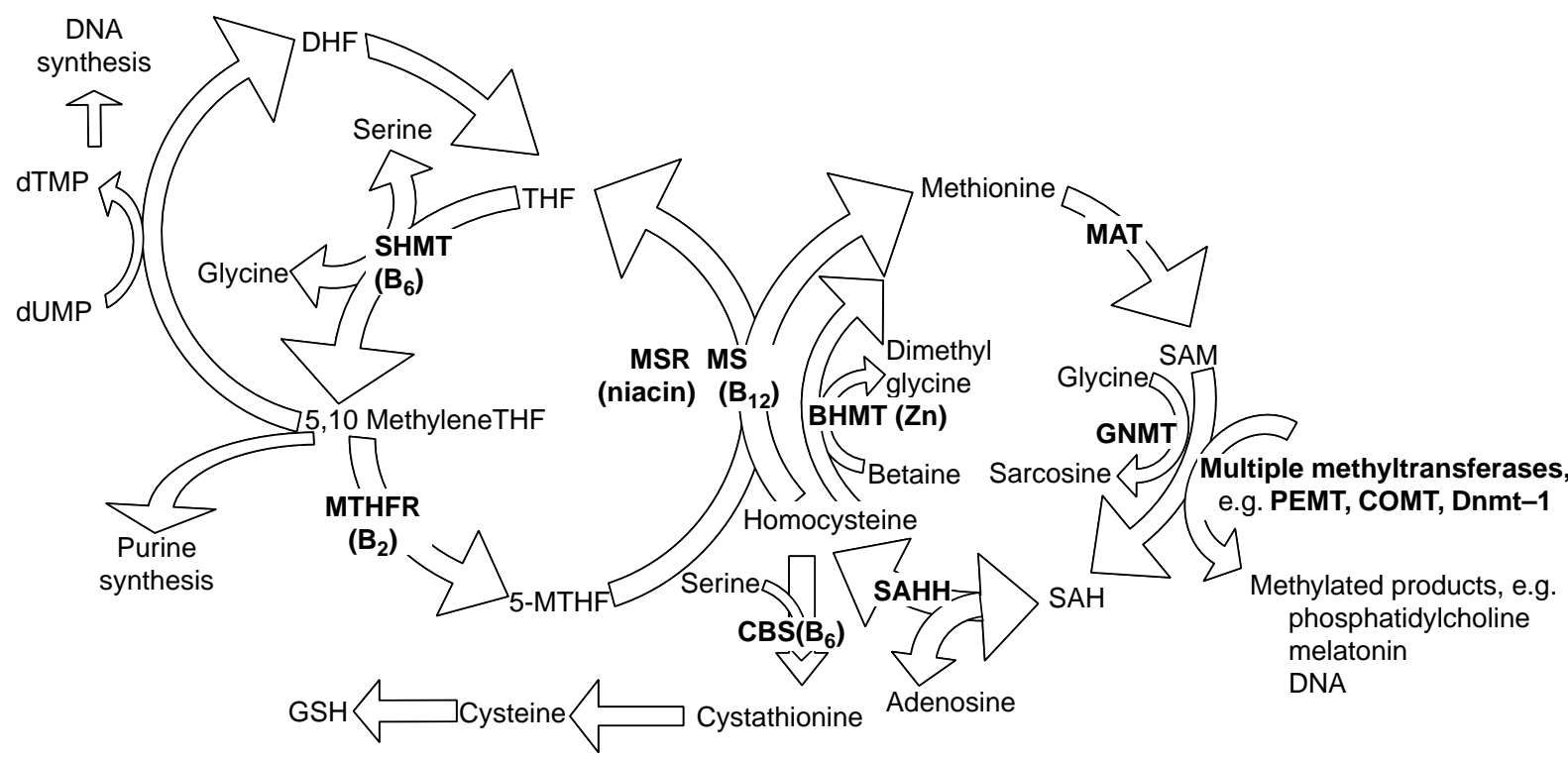

Fig. 1. The interaction between folate metabolism, the methionine cycle and methyl group metabolism. DHF, dihydrofolate; THF, tetrahydrofolate; SHMT, serine hydroxymethyltransferase; MAT, methionine adenosyltransferase; MSR, methionine synthase reductase; MS, methionine synthase; SAM, S-adenosylmethionine; BHMT, betaine-homocysteine methyltransferase; GNMT, glycine N-methyltransferase; MTHFR, methylenetetrahydrofolate reductase; PEMT, phosphatidylethanolamine; COMT, catechol-O-methyltransferase; Dnmt-1, DNA methyltransferase-1; 5-MTHF, 5-methyltetrahydrofolate; CBS, cystathionine $\beta$-synthase; SAHH, SAH hydrolase; SAH, S-adenosylhomocysteine. 
activity. Conversely, high SAM concentrations inhibit MTHF reductase, reducing the concentration of 5-MTHF and releasing the inhibition of GNMT, which then reduces SAM levels. If SAM concentrations fall, MTHF reductase activity increases, producing more 5-MTHF, which inhibits GNMT, preserving SAM for other essential transmethylation reactions (Rowling et al. 2002) (Fig. 2). Hence, under normal circumstances the SAM:SAH ratio is tightly regulated. However, despite these and other regulatory mechanisms, perturbations in vivo are caused by dietary excess or deficiency of methionine or choline, or of cofactor vitamins $\mathrm{B}_{2}$, niacin, $\mathrm{B}_{6}, \mathrm{~B}_{12}$ or folic acid, and/or enzyme polymorphisms.

\section{Methylation and mental illness}

Most studies correlating symptoms of psychiatric illness and disturbed one-carbon metabolism have examined individual aspects of the cycle; hence, the evidence is presented accordingly. However, disturbance in one part of the cycle affects the whole cycle.

\section{Serine, glycine and serine hydroxymethyltransferase}

Serine is the main one-carbon donor via the conversion of serine to glycine by SHMT (Cook, 2001; Davis et al. 2004). Serine also participates in the trans-sulfuration pathway as a cofactor for cysteine synthesis, and subsequently GSH, taurine and sulfate.

Glycine and D-serine are obligatory co-agonists at the $\mathrm{N}$-methyl-D-aspartate (NMDA)-type glutamate receptors, which are believed to play a key role in the pathophysiology of schizophrenia (Heresco-Levy et al. 1999; Olney et al. 1999). The glutamate hypothesis derives from observations that phencyclidine, ketamine and other non-competitive
NMDA receptor antagonists produce a psychosis more closely matching schizophrenia than the dopamine agonist model. Disruptions of glutamatergic neurotransmission and glutamate receptor expression have been observed in post mortem studies (Tsai et al. 1998; Olney et al. 1999).

Early studies found significantly increased plasma serine in drug-free psychotics, with decreased SHMT activity (Waziri \& Mott, 1986), and significantly increased serine and glycine concentrations in medial and temporal lobes of schizophrenic brains post mortem, and increased $\mathrm{K}_{\mathrm{m}}$ of SHMT (Waziri et al. 1992). A double-blind placebocontrolled (DBPC) cross-over trial of high-dose glycine in treatment-resistant schizophrenia found that $0.8 \mathrm{~g}$ glycine/ $\mathrm{kg}$ per d (average $60 \mathrm{~g} / \mathrm{d}$ ) significantly reduced negative symptoms as measured by the Positive and Negative Syndrome Scale by 30 (SD 16)\% $(P<0 \cdot 001)$, and significantly improved Brief Psychiatric Rating Scale scores by 30 (SD 18) \% $(P<0.001)$. (Positive symptoms denote visual, auditory and/or tactile hallucinations and delusions; negative symptoms denote social withdrawal.) Low, but within normal range, pre-treatment serum glycine significantly predicted treatment response (Heresco-Levy et al. 1999). This study followed two other DBPC trials in schizophrenics (15 and $30 \mathrm{~g}$ glycine/d), which both saw symptom improvements.

D-Serine $(30 \mathrm{mg} / \mathrm{kg}$ per d) supplementation significantly improved positive, negative and cognitive symptoms of schizophrenia in a DBPC trial in Taiwanese patients (Tsai et al. 1998). D-Serine crosses the blood-brain barrier more easily than glycine, allowing a lower effective dose, but since glycine can be converted in vivo to $\mathrm{D}$-serine and vice versa, the source of clinical effects is unclear. In a metaanalysis of eighteen DBPC trials of glycine $(n 7)$, D-serine ( $n$ 2), D-cycloserine ( $n$ 7), and ampakine CX516 ( $n$ 2) in addition to anti-psychotics, treatment with glycine or D-serine moderately but significantly improved negative symptom scores ( $n$ 132; fixed effect model standardised

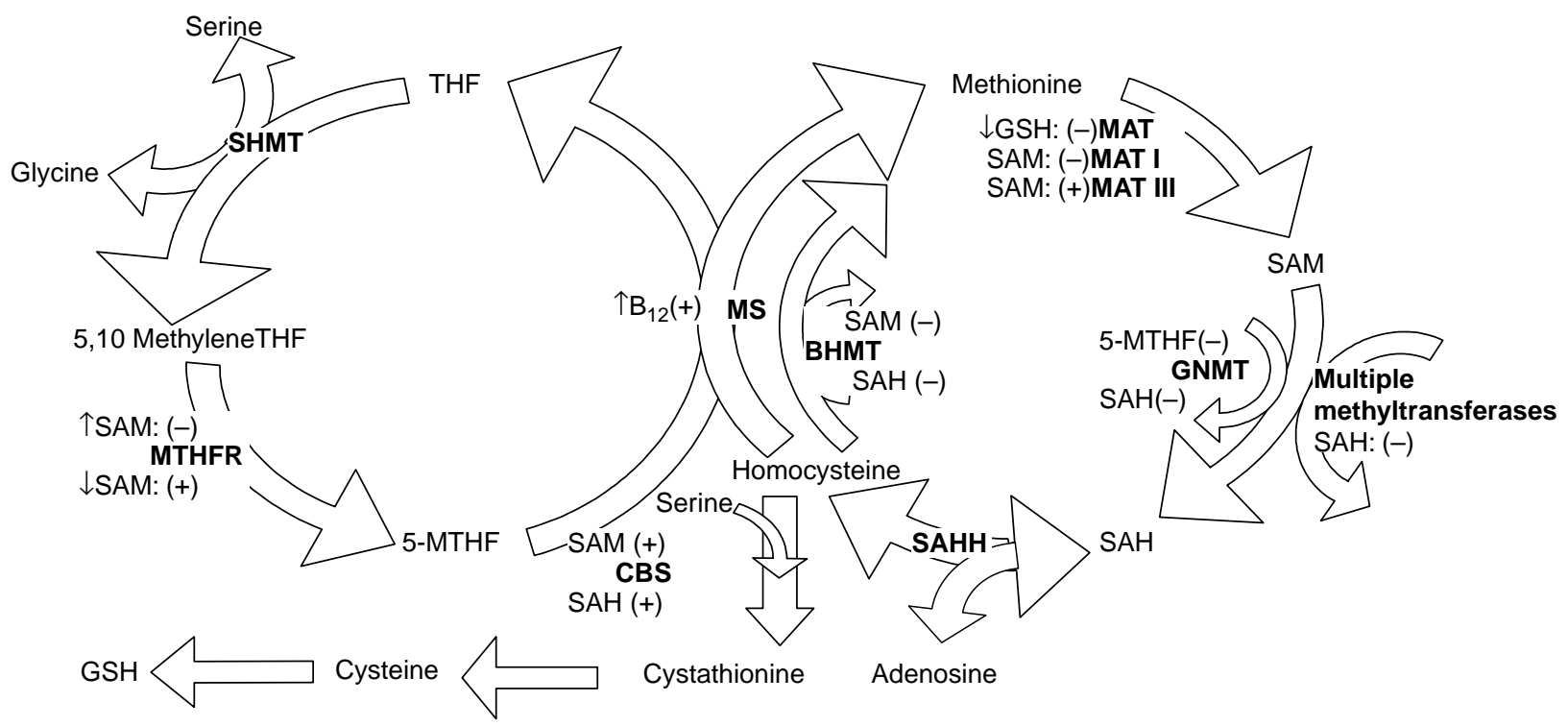

Fig. 2. Regulation of methyl-group metabolism. THF, tetrahydrofolate; SHMT, serine hydroxymethyltransferase; MAT, methionine adenosyltransferase; SAM, S-adenosylmethionine; MS, methionine synthase; BHMT, betaine-homocysteine methyltransferase; 5-MTHF, 5-methyltetrahydrofolate; SAH, S-adenosylhomocysteine; GNMT, glycine N-methyltransferase; MTHFR, methylenetetrahydrofolate reductase; CBS, cystathionine $\beta$-synthase; SAHH, SAH hydrolase; $\downarrow$, low; $(-)$, inhibits; $(+)$, stimulates; $\uparrow$, high. 
mean difference $-0.66 ; 95 \%$ CI $-1.02,-0.29$; $P=0.0004)$ (Tuominen et al. 2005).

More recently, a comparison of ninety-one US schizophrenic out-patients with subjects of the Framingham Offspring Study found a significant inverse correlation between serum glycine levels and the severity of negative symptoms as measured by the Scale for the Assessment of Negative Symptoms (SANS) in patients. Serum folate was significantly lower in patient smokers and non-smokers compared with matched controls. Low serum folate $(<3 \mathrm{ng} / \mathrm{ml})$ was present in $16.4 \%$ of patients $v .1 .7 \%$ of controls, with no significant difference in Hcy levels. Multiple regression of sex, serum folate, glycine, serine, cobalamin and total Hcy concentrations, and cigarettes per $\mathrm{d}$, revealed that only serum glycine concentration in smokers and non-smokers, and folate concentration in nonsmokers, significantly predicted SANS total scores in patients $(P<0.05)$. No relationship was found between folate concentration and the serine:glycine ratio, suggesting no relationship with SHMT activity (Goff et al. 2004).

Sarcosine is a potent antagonist at the GlyT-1 site, and may reduce glycine re-uptake. A DBPC trial of sarcosine $(2 \mathrm{~g} / \mathrm{d})$ as an adjunct to normal therapy in thirty-eight schizophrenic patients revealed a significant effect of sarcosine on measures of positive, negative, cognitive and general psychiatric symptoms (Tsai et al. 2004).

\section{Methylenetetrahydrofolate reductase}

The most well-researched enzyme single nucleotide polymorphism (SNP) in the methionine cycle is the C677T variant of riboflavin-dependent MTHF reductase; the TT variant enzyme has about $35 \%$ of normal activity. TT homozygotes benefit from higher folate intake which prolongs enzyme-cofactor binding, increasing overall activity.

MTHF reductase TT and CC homozygotes metabolise folate differently, especially in the presence of riboflavin deficiency (Hustad et al. 2000; McNulty et al. 2002). Low MTHF reductase activity causes formylTHF accumulation at the expense of 5-MTHF, favouring nucleotide synthesis over Hcy re-methylation and ensuring optimum DNA synthesis and repair during adequate folate intake. Conversely, there is some evidence that folate deficiency further reduces 5-MTHF supply for re-methylation, which may lead to global DNA hypomethylation which is associated with carcinogenesis (Ueland et al. 2001). Carrying the TT genotype appears to modulate the risk of developing cancer, with varying effects depending on the cancer site. Preliminary evidence suggests that TT homozygotes may have an increased risk of breast cancer, cervical neoplasia and endometrial cancer, and a decreased risk of acute adult leukaemia and colorectal cancer (Kim, 2000). Curiously, schizophrenics appear to have a reduced cancer risk, in spite of very high smoking rates, low exercise, and poorer diet (Cohen et al. 2002; Grinshpoon et al. 2005).

In a Japanese psychiatric population (297 schizophrenic, thirty-two major depression, forty BPD; 419 controls), the TT frequency was significantly greater amongst patients with schizophrenia (odds ratio (OR) $1.9 ; P=0.0006)$ and major depression (OR 2.8; $P=0.005$ ) (Arinami et al. 1997). In a Canadian population (forty-three treatmentresponsive schizophrenics, sixty-two non-responders $v$. ninety controls) the TT frequency was significantly greater in the treatment-responsive group (Joober et al. 2000), but no difference in $\mathrm{T}$ allele distribution or TT genotype was found between 210 Spanish schizophrenics and 218 controls (Virgos et al. 1999). However, a recent meta-analysis of six studies (1119 patients, 1308 controls) found that TT homozygotes had a significantly increased risk of developing schizophrenia (OR 1.48; 95 \% CI 1.18, 1.86) (Lewis et al. 2005).

Another MTHF reductase SNP, A1298C, reduces enzyme activity by $60 \%$ in CC genotypes; double homozygotes (677TT/1298CC) are very rare. Found in the SAM-binding region, the A1298C variant enhances SAM-mediated enzyme inhibition. In Canadians heterozygous for both SNP, lymphocyte MTHF reductase activity was 50-60\% of CC/AA individuals (Weisberg et al. 1998). Two studies examined the combined MTHF reductase genotypes in schizophrenia. 677CT and TT genotypes were more frequent among ninety-nine male and 135 female Korean schizophrenic patients than controls (OR 2.25; $P<0.05$ ), but no difference was found in the frequency of the A1298C SNP (Na \& Lee, 2004). Likewise, in a Turkish population of Diagnostic and Statistical Manual (DSM)-IV schizophrenic and schizoaffective neuroleptic-responders (130 patients $v$. 226 matched controls), the TT genotype was more frequent in patients (OR 2.504; $95 \%$ CI 1.276, 4.915; $P=0.006)$, but in this population the compound TT/AA genotype further increased schizophrenia risk (OR 3.157; $95 \%$ CI 1.522 , 6.545; $P=0 \cdot 001)$ (Sazci et al. 2003).

\section{Folic acid}

5-MTHF is actively transported into the nervous system at the choroid plexus, and its entry is limited by an efficient blood-brain barrier mechanism (Reynolds, 2002). Cerebral spinal fluid (CSF) folate levels are about 3-fold higher than serum folate, indicating the importance of folate to the CNS, yet folate deficiency is the most common vitamin deficiency in the developed world.

Plasma folate $\leq 2.5 \mathrm{ng} / \mathrm{ml}$ or erythrocyte folate $<200 \mathrm{ng} / \mathrm{ml}$ was found in $15-38 \%$ of depressed patients from several patient cohorts (Alpert \& Fava, 1997). Dietary intake of folate and depressive symptoms were also associated in a cross-sectional study of Finnish middleaged men. Those in the lowest third of energy-adjusted folate intake had a higher risk of being depressed (OR 1.67; 95\% CI 1.19, 2.35; $P=0.003$ ) (Tolmunen et al. 2003). The recent draft report from the Scientific Advisory Committee on Nutrition on folate and disease prevention (available at http://www.sacn.gov.uk) cited a prospective study of 2313 Finnish men (42-60 years) followed-up for an average of 13 years (Tolmunen et al. 2004). A higher risk of a discharge diagnosis of depression (relative risk $3.04 ; 95 \%$ CI $1.58,5.86$ ) was found in those with an energy-adjusted folate intake below the median $v$. those above the median (mean energy-adjusted folate intake $256 \mu \mathrm{g} / \mathrm{d}$; median intake not stated). 
Of forty-six patients with severe DSM-III depression, twenty-four had significantly higher plasma total Hcy levels than normal $(P<0.01)$, or neurologically diseased $(P<0.001)$, control groups. Those with high plasma total Hcy had the lowest erythrocyte, serum and CSF folate levels. The low folate-high total Hcy group also had significantly lower CSF concentrations of the monoamine metabolites 5-hydroxyindole acetic acid, homovanillic acid and 3-methoxy-4-hydroxyphenyl glycol (derived from serotonin, dopamine and noradrenaline respectively). An interesting observation was that CSF folate correlated with serum, but not erythrocyte, folate in both the whole depressed group $(r 0.424 ; P<0.02)$, and in the neurological controls ( $r$ 0.747; $P<0.001)$, suggesting that serum folate is a reliable marker for CSF folate (Bottiglieri et al. 2000).

Folate status also modulates anti-depressant treatment response; among 213 out-patients with major depressive disorder, those with low serum folate at baseline were less likely to respond to fluoxetine $(20 \mathrm{mg} / \mathrm{d}$ for 8 weeks $)$ than those with normal folate, as assessed by investigators blind to status. Furthermore, folate therapy alone has proved an effective treatment for depression; an open-label trial of $50 \mathrm{mg}$ methylfolate/d in twenty elderly patients with depressive disorders, of whom only two were deemed folate deficient, was associated with an $81 \%$ response rate over 6 weeks (Alpert \& Fava, 1997).

Of 123 patients with major depression or schizophrenia, $33 \%$ had borderline or explicit folate deficiency. In a DBPC trial of $15 \mathrm{mg}$ methylfolate/d for 6 months in deficient patients (twenty-four depressed, seventeen schizophrenic), combined with psychotropic medication, methylfolate significantly improved clinical and social recovery in both patient groups $v$. placebo (Godfrey et al. 1990). Although there were no significant group differences in the distribution of psychotropic drugs taken, the use of a variety of drugs is a confounding factor in this study.

When thirty-five Dutch schizophrenics were compared with 104 controls, serum folate $<10$ th percentile $(n 10)$, and erythrocyte folate $>95$ th percentile ( $n$ 13) of control levels increased the adjusted risk of schizophrenia (OR 6.9, $95 \%$ CI $2 \cdot 1,23 \cdot 1, P<0 \cdot 01$; OR $10 \cdot 8,95 \%$ CI $2 \cdot 8,41 \cdot 3$, $P<0.001$ respectively) (Muntjewerff et al. 2003). This folate profile is consistent with reduced MTHF reductase activity, but no increase of the C677T SNP was found; however, the TT frequency in controls $(18 \%)$ was higher than in another Dutch population $(8 \%)$, and the number of patients was small.

An American study (post-folate fortification) found significantly lower serum folate in ninety-one schizophrenic out-patients compared with controls from the Framingham Offspring Study (5.74 v. $10.00 \mathrm{ng} / \mathrm{ml} ; P<0.001)$. Folate levels of smokers $(4.87 \mathrm{ng} / \mathrm{ml})$ and non-smokers $(7.21 \mathrm{ng} / \mathrm{ml})$ were both significantly lower than controls. Furthermore, folate concentration inversely correlated with SANS total score, significantly in non-smokers but not in smokers (Goff et al. 2004).

A study of Israeli schizophrenic in-patients from a socially deprived area found $75 \%$ of male and $65 \%$ of female patients had low plasma folate levels $(<3.7 \mathrm{ng} / \mathrm{ml})$ (Stahl et al. 2005). Interestingly, only $6.4 \%$ of the male patients displayed abnormal mean corpuscular volume, suggesting that folate supply for DNA synthesis was maintained at the expense of the re-methylation pathway. The authors comment that a similar study in a less disadvantaged area of Israel found less folate deficiency $(5.6 \%<2.5 \mathrm{ng} / \mathrm{ml}$ v. $41 \%<2.5 \mathrm{ng} / \mathrm{ml})$, and that low folate is therefore not a constant feature of schizophrenia. However, the latter patients had low cobalamin, suggesting that the common denominator could have been reduced Hcy re-methylation due to cofactor deficiency.

It is interesting that depression is more frequently associated with folate deficiency than cobalamin deficiency, when both reduce MS activity. This could simply be because folate deficiency is more common, but may be mediated by GNMT. In cobalamin deficiency, 5-MTHF is trapped and levels increase, inhibiting GNMT and conserving SAM for other methyltransferase activities. However, when cobalamin is adequate and folate is deficient, GNMT remains active, competing with other methyltransferases for a reduced SAM supply. The mechanism by which folate influences mood is currently unknown, but the effects on SAM supply may be a contributing factor.

Folate supplementation above a therapeutic window may actually worsen depressive symptoms in patients (Alpert \& Fava, 1997). Doses of $15 \mathrm{mg} / \mathrm{d}$ have been associated with mental changes in healthy volunteers. Sleep alterations, malaise, hyperactivity and irritability have been reported; symptoms similar to those of deficiency (Hunter et al. 1970). An animal study also suggests that folate exerts a U-shaped pattern of effect; when low CSF 5-hydroxyindole acetic acid levels were found in patients with folateresponsive depression, brain serotonin was determined in rats fed folate-deficient or excess-folate diets; both had reduced serotonin (Botez et al. 1979).

\section{Methionine synthase and cobalamin}

Only two human enzymes use cobalamin as a cofactor; MS and methylmalonyl mutase. MS re-methylates Hcy, using 5-MTHF as the methyl donor, and requires niacindependent MS reductase to reductively activate MS, since the enzyme-vitamin complex is susceptible to oxidation. When MS activity is impaired, THF cannot be regenerated from 5-MTHF, resulting in reduced nucleotide biosynthesis and macrocytosis.

The brain has an absolute requirement for cobalamin for Hcy re-methylation since the BHMT pathway is absent. Although brain re-methylation has not been quantified, an animal study suggests that it must be substantial: when MS was inactivated by placing pigs in an atmosphere containing $15 \%$ nitrous oxide for $7 \mathrm{~d}$, SAH increased 10-fold in the brain and spinal cord. Furthermore, MS recovery (via new enzyme synthesis) took several days in liver, kidney and brain, and $>2$ weeks in spinal cord. Changes in MS activity were closely correlated with the SAM:SAH ratio in the brain, but not the liver, confirming the importance of MS to brain function (Molloy \& Weir, 2001). Hypoxia also inactivates $\mathrm{MS}$, and mountain climbers suffering from hypoxia report hallucinations, a prominent symptom of psychosis.

Interestingly, an in vitro study using radiolabelling techniques demonstrated that supplementary cobalamin 
increases MS activity 2-3.5-fold, even when no deficiency exists, enhancing Hcy flux through the transmethylation pathway, without affecting methylmalonyl mutase activity (Oltean \& Banerjee, 2003).

Severe cobalamin deficiency causes upper spinal cord degeneration, and eventually death. Neuropsychiatric symptoms often precede haematological symptoms of deficiency (Lindenbaum et al. 1988; Weir \& Scott, 1995; Gultepe et al. 2003). A review of the literature showed that psychiatric symptoms might be the initial or only sign of deficiency; most common signs are depression, mania, psychosis, cognitive impairment and obsessive-compulsive disorder (Durand et al. 2003).

In the Rotterdam Study, 3884 elderly individuals were screened for depressive symptoms. Of these subjects, 112 fulfilled the DSM-IV criteria for depressive disorders. Cobalamin-deficient subjects were significantly more likely to have a depressive disorder than controls (adjusted OR 1.69; $P=0.02 ; 95 \%$ CI 1.10, 2.56) (Tiemeier et al. 2002).

It should be noted that serum holotranscobalamin or methylmalonate are better markers of active cobalamin status than serum cobalamin.

\section{Methionine}

The finding that a methionine load exacerbates symptoms of psychosis in schizophrenic patients is frequently cited in the literature. However, the original studies used methionine in combination with monoamine oxidase inhibitors (for a review, see Wyatt et al. 1971), which are now known to exacerbate psychosis.

In a DBPC cross-over study comparing methionine (without monoamine oxidase inhibitors) and glycine treatment in schizophrenic patients, seven out of eleven patients showed a marked exacerbation of psychotic symptoms when fed $20 \mathrm{~g}$ methionine/d for 1 week, followed by $10 \mathrm{~g} / \mathrm{d}$ for 1 week. No patients reacted negatively to glycine, whilst one patient showed significant improvement with methionine (Antun et al. 1971). The improved sociability of four patients noted by ward staff may have been due to the effect of glycine on negative symptoms, which were unknown at the time, and hence confounded this study.

However, CSF methionine was significantly higher in thirty-six (sixteen female, twelve male) psychotic patients $v$. twenty-five controls. CSF methionine levels in drug-naive patients (4.3 (SD 1.3) $\mu \mathrm{mol} / \mathrm{l} ; n$ 14) were similar to other patients (4.5 (SD 1.4) $\mu \mathrm{mol} / \mathrm{l} ; n$ 22), and all patients had significantly higher CSF methionine than controls (2.8 (SD 1.0) $\mu \mathrm{mol} / 1 ; P<0.00001)$. Ten patients had levels higher than any controls (Regland et al. 2005).

\section{Methionine adenosyltransferase}

When ninety psychiatric patients were investigated on admission to hospital, the $\mathrm{V}_{\max }$ of erythrocyte methionine adenosyltransferase activity was low in depressed and schizophrenic patients, and over-active in manic patients. After pharmacological treatment the $\mathrm{V}_{\max }$ values were normalised in all patient groups (Tolbert et al. 1988).

\section{S-adenosylmethionine}

SAM is the methyl-donor in the rate-limiting step in the synthesis of serotonin, dopamine and noradrenaline. Studies in Alzheimer's, HIV and depressed patients have shown that orally administered SAM crosses the blood-brain barrier and increases CSF SAM concentrations. The efficacy of SAM in treating depression has been demonstrated in more than forty clinical trials, and two reviews of the evidence concluded that SAM is as effective as standard antidepressants (imipramine, chlorimipramine, nomifensine, and minaprine) with significantly fewer side effects (Bottiglieri, 2002; Mischoulon \& Fava, 2002).

Two multicentre, randomised DBPC studies (double dummy design) compared SAM treatment with the tricyclic anti-depressant imipramine in major depression. In the first, 143 patients received up to $1600 \mathrm{mg} \mathrm{SAM} / \mathrm{d}$ and six tablets per d of imipramine placebo, whilst 138 received $150 \mathrm{mg}$ imipramine/d and SAM placebo, for 6 weeks. In the second, imipramine ( $n$ 148) was compared with $400 \mathrm{mg} \mathrm{SAM} / \mathrm{d}$, injected intramuscularly ( $n$ 147) (the placebo SAM injection contained mannitol). In both studies, SAM treatment was as effective as imipramine but the safety and tolerability of SAM was significantly superior to imipramine $(P=0 \cdot 001)$ (Chiaie et al. 2002).

SAM is also reported to improve cognitive deficits in dementia, and is effective for treating depression associated with Parkinson's disease, alcoholism and the puerperium. However, SAM supplementation mediates a switch from depression to mania in some patients with BPD (Bottiglieri, 2002; Mischoulon \& Fava, 2002). A small study found a $50 \%$ decrease in blood levels of SAM in acute, but not chronic, schizophrenics $v$. controls $(P<0.001)$ (Andreoli $\&$ Maffei, 1975), but no recent data are available.

\section{Methyltransferase activity}

Methyltransferases catalyse the transfer of a methyl group from SAM to a recipient molecule, producing SAH and the methylated product. SAH competitively binds to SAM binding sites, inhibiting methyltransferase activity, hence the SAM:SAH ratio describes the cellular methylation potential. The inhibition of methyltransferase activity varies: in vitro evidence demonstrated that at a SAM level of $2.7 \mu \mathrm{mol} / 1$, increasing SAH from 0.8 to $6.7 \mu \mathrm{mol} / 1$ (the SAH level of hyperhomocysteinaemic uraemic patients) reduced phosphatidylethanolamine (PE) methyltransferase (PEMT) activity by $53 \%$ (in rat liver), and catechol- $O$-methyltransferase (COMT) activity by $69 \%$ (in human brain). Other methyltransferases with CNS effects include histamine $N$-methyltransferase (inactivates histamine), phenylethanolamine $N$-methyltransferase (synthesises adrenaline), arginine methyltransferase (methylates myelin basic protein), and hydroxy-indole- $O$ methyltransferase (synthesises melatonin) (Clarke \& Banfield, 2001). Interestingly insomnia, a common symptom of psychiatric illness, is associated with melatonin depletion. In rats, folate deficiency decreased pineal melatonin concentration, and nocturnal urinary excretion of melatonin metabolites (Fournier et al. 2002). 
COMT inactivates circulating catechol hormones, catechol neurotransmitters (for example, dopamine, adrenaline, noradrenaline), and xenobiotic catecholamines (for example, caffeic acid, L-dopa) by methylating their catechol moieties. An SNP of the COMT gene (val ${ }^{158}$ met or $\mathrm{H} / \mathrm{L}$ ), accounts for a 4-fold variation in enzyme activity, the val allele having four times the activity of the met allele. The population distribution is about $33 \%$ $\mathrm{val} / \mathrm{val}, 46 \% \mathrm{val} / \mathrm{met}$, and $21 \% \mathrm{met} / \mathrm{met}$.

COMT genotype distribution did not vary between 181 Alzheimer's patients and 208 age-matched controls; however, among patients with psychosis $(32.6 \%), 88.1 \%$ were COMT $\mathrm{H}$ carriers $(P<0 \cdot 01)$. The adjusted $\mathrm{OR}$ for psychosis risk in COMT H carriers was 2.66 (95\% CI 1.6, 6.62) (Borroni et al. 2004). The $\mathrm{H}$ allele was also significantly associated with phobic anxiety development in a population of 1234 women. The OR for scoring $\geq 6 v .0$ or 1 on the phobic anxiety scale of the Crown-Crisp Experimental Index was $1.99(95 \%$ CI 1.17, 3.40) for the HH genotype (McGrath et al. 2004). Conversely, a meta-analysis found only a weak association between the SNP and schizophrenia in European, but not Asian, patients (Glatt et al. 2003). Most recently, a large association study in a Han Chinese population found no effect of COMT polymorphism on schizophrenia risk, and a meta-analysis of all studies to date came to the same conclusion (Fan et al. 2005).

However, increased COMT activity does negatively influence the performance of frontally mediated cognitive tasks. A higher number of met alleles was associated with fewer perseverative errors in the Wisconsin Card Sorting Test in healthy individuals, but their schizophrenic siblings all performed like val/val individuals regardless of genotype (Rosa et al. 2004). Furthermore, when thirty schizophrenics were assessed before and after anti-psychotic treatment (olanzapine for 8 weeks), met allele load significantly predicted improvements in working memory, prefrontal cortex activation, and negative symptoms (Bertolino et al. 2004). The working memory improvements in met carriers were confirmed in schizophrenics taking a range of antipsychotics in another small study (Weickert et al. 2004).

\section{Methylation demand}

Increasing methyltransferase substrate levels imposes a greater methylation demand, resulting in increased SAM consumption and Hcy production (Rogers et al. 2003; Stead et al. 2004). This has been demonstrated in L-dopa-treated Parkinson's patients, and confirmed in animal studies. L-Dopa is a COMT substrate, and L-dopa-treated patients have increased plasma total Hcy (Miller et al. 2003; Muller et al. 2004). Interestingly, symptoms of psychosis and mood changes indistinguishable from those seen in schizophrenia often develop in Parkinson's patients after long-term L-dopa treatment, or following an increase in dose (Doraiswamy et al. 1995). Likewise, methylation demand and Hcy production is also increased by: high coffee consumption due to the $O$-methylation of chlorogenic acid, a polyphenol in coffee; high-dose niacin therapy given for lipid reduction (Stead et al. 2004); and a high-fat high-cholesterol diet due to increased PEMT activity (Noga \& Vance, 2003).
The high activity COMT val/val genotype consumes four times as much SAM as the met/met genotype. This high methylation demand may detrimentally affect memory by impacting on other SAM-dependent neurotransmitter pathways. Decreased SAM availability for the de-activation of neurotransmitters may even lead to increased endogenous hallucinogens, as proposed by the transmethylation hypothesis (Hoffer et al. 1954); the hallucinogen adrenochrome is a by-product of adrenalin which is inactivated by COMT. Lastly, stress causes the production of large amounts of biogenic amines, which also increases methylation demand (Levi \& Waxman, 1975).

A kinetic study of the transfer rate of the radio-tagged methyl group of methionine to $\mathrm{CO}_{2}$ in breath showed that the rate was three times slower in seven schizophrenics $v$. seven controls, with no overlap of data points (Sargent et al. 1992). Since surplus methyl groups are oxidised to $\mathrm{CO}_{2}$ via the methylation of glycine by GNMT, this study suggests that reduced SAM synthesis or an increased methylation demand is associated with schizophrenia.

\section{Homocysteine}

The betaine pathway of Hcy re-methylation is absent in the brain, and the activity of cystathionine $\beta$-synthase is about $20 \%$ of hepatic cystathionine $\beta$-synthase activity, whilst cystathionine $\gamma$-lyase is believed to be absent (Weir \& Molloy, 2000). Hence, brain tissue has only three ways of metabolising Hcy: recycling via MS; catabolism to cystathionine; export into the circulation.

Recent studies found significantly increased plasma total Hcy levels in DSM-III depression (Bottiglieri et al. 2000), BPD (Osher et al. 2004) and schizophrenia (Susser et al. 1998; Levine et al. 2002; Na \& Lee, 2004; Applebaum et al. 2004), with one negative study in schizophrenics (Muntjewerff et al. 2003). However, none of the studies gave full data on the many factors known to increase plasma total Hcy, for example, smoking, coffee intake, and low folate or cobalamin status. Nevertheless, a DBPC cross-over trial of Hcy-lowering nutrients ( $2 \mathrm{mg}$ folic acid, $25 \mathrm{mg}$ pyridoxine and $400 \mu \mathrm{g} \mathrm{B}_{12}$ once per $\mathrm{d}$ for 3 months) in highly symptomatic schizophrenics with plasma total Hcy $>15$ $\mu \mathrm{mol} / \mathrm{l}$ (seventeen male, one female) had a significant effect on positive $(+2.4$ points), negative $(+1.6$ points $)$ and general psychopathology ( +3.4 points) subscales of Positive and Negative Syndrome Scale scores (Shumeiko et al. 2003).

Several mechanisms of Hcy neurotoxicity have been proposed including NMDA receptor activation or hypofunction, enhanced oxidative stress, DNA damage and apoptosis. Hcy is a partial agonist at the NMDA glutamate site, and a partial antagonist at the glycine co-agonist site. However, whereas Hcy was neurotoxic at concentrations of $10-100 \mu \mathrm{mol} / \mathrm{l}$, causing over-stimulation of the NMDA receptor when glycine was elevated (as in stroke or head trauma), under normal conditions Hcy was not toxic until in the millimolar range (Lipton et al. 1997). Furthermore, a recent study found no difference in CSF Hcy levels between forty-one schizophrenic patients and twenty-nine controls (Levine et al. 2005). Thus, it seems likely that elevated plasma total Hcy is a biomarker of disturbed methylation status in neuropsychiatric disorders, rather than the cause of 
psychiatric disturbance, although high levels should clearly be treated to reduce the high risk of CVD in schizophrenics.

\section{Restoring normal methylation}

A recent study of methylation factors in twenty autistic children $v$. thirty-three controls found significantly reduced plasma levels of methionine, SAM, SAM:SAH, total Hcy, cystathionine, cysteine, total glutathionine and total glutathionine:GSSG, along with significantly increased levels of SAH, adenosine and GSSG (Table 1). This profile describes reduced methylation capacity and increased oxidative stress. An intervention in eight children $(800 \mu \mathrm{g}$ folinic acid and $1000 \mathrm{mg}$ betaine twice daily for 3 months), brought the methionine cycle metabolites within the normal range, and the addition of twice-weekly injections of $75 \mu \mathrm{g}$ methylcobalamin $/ \mathrm{kg}$ for a further 1 month normalised the trans-sulfuration pathway metabolites. The researchers also noted behavioural improvements, but these details have not yet been published (James et al. 2004).

\section{Discussion}

Whilst most aspects of one-carbon metabolism have been associated with psychiatric symptoms, the most replicated biomarkers to date appear to be low serum folate and high plasma total Hcy. However, psychiatric complications do not occur in most folate-deficient-high total Hcy subjects. Hence a combination of factors may be necessary to elicit psychiatric symptoms, for example, a genetic pre-disposition mediated by one or more SNP, plus poor diet, and a stress- or exogenous substance-induced high methylation demand. Notably, the plasma SAM:SAH ratio has not been measured in psychiatric patients and, as a more sensitive indicator of methylation status than plasma total Hcy, may be informative.

\section{Methylation and phospholipids}

\section{Methylation and phospholipid metabolism}

Dysregulation of phospholipid metabolism in schizophrenia, major depression and BPD is well documented
(Horrobin, 1999; Peet \& Bennett, 1999; Sarmiento et al. 1999). Schizophrenia is associated with reduced erythrocyte membrane arachidonic acid and DHA, hypothesised to be due to the over-activity of phospholipase A2 (PLA2) and $\mathrm{PLC}$ that release arachidonic acid from the $\mathrm{Sn}-2$ position of phosphatidylcholine (PC).

$\mathrm{PC}$ is produced in the liver via three pathways: transfer of phosphocholine to 1,2-diacylglycerol via cytidine diphosphate (CDP)-choline (the Kennedy pathway) which is choline dependent; sequential methylation of PE catalysed by PEMT, consuming three molecules of SAM; acylation of lysophosphocholine. The pool of PC produced via transmethylation, although much smaller, is more biologically active than the CDP-choline-derived pool (Hirata \& Axelrod, 1980; Watkins et al. 2003).

The PEMT pathway is responsible for about $30 \%$ of hepatic PC production and, since the synthesis of each PC molecule produces three molecules of $\mathrm{SAH}$, significantly contributes to plasma total Hcy levels. Observations in Pemt -/- mice found a $50 \%$ reduction in plasma total Hcy compared with controls. Hepatic methylation enzyme activities did not differ from Pemt $+/+$ mice, and SAM was not depleted in Pemt -/- cells, hence the PEMT pathway appears to be responsible for about $50 \%$ of plasma total Hcy load in mice (Noga et al. 2003).

Significantly, a stable-isotope study demonstrated a profound distinction in PC profiles between those produced via the PEMT and CDP-choline pathways. PC molecules produced from the CDP-choline pathway were mainly comprised of medium-chain, saturated fatty acids, whilst those derived from the PEMT pathway contained significantly more long-chain PUFA (LCPUFA) (DeLong et al. 1999). Furthermore, the quantitative profiling of lipid metabolites in Pemt -/- mice demonstrated a key role for the PEMT pathway in regulating the distribution of arachidonic acid and DHA to peripheral tissues (Watkins et al. 2003). PEMT deficiency significantly reduced: hepatic and plasma PC DHA content; plasma PC arachidonic acid and stearic acid; plasma cholesteryl ester DHA and arachidonic acid. These studies suggest that PEMT activity is almost solely responsible for the mobilisation of DHA and arachidonic acid into plasma, and hence to peripheral

Table 1. Comparison of plasma one-carbon cycle metabolites in control children and autistic children, pre- and post-treatment with vitamin cofactors (adapted from James et al. 2004) (Mean values, standard deviations and ranges)

\begin{tabular}{|c|c|c|c|c|c|c|c|c|}
\hline & \multicolumn{3}{|c|}{ Control children (n 33) } & \multicolumn{3}{|c|}{ Autistic children (n 20) } & \multicolumn{2}{|c|}{ Post-treatment ( $n$ 8) } \\
\hline & Mean & SD & Range & Mean & SD & Range & Mean & SD \\
\hline Methionine $(\mu \mathrm{mol} / \mathrm{l})$ & 31.5 & $5 \cdot 7$ & $23-48$ & $19 \cdot 3^{\star \star \star *}$ & $9 \cdot 7$ & $15-25$ & 30.9 & $7 \cdot 7$ \\
\hline SAM (nmol/l) & $96 \cdot 9$ & 12 & $77-127$ & $75 \cdot 8^{\star \star}$ & $16 \cdot 2$ & $68-100$ & $101 \cdot 6$ & $20 \cdot 5$ \\
\hline $\mathrm{SAH}(\mathrm{nmol} / \mathrm{l})$ & $19 \cdot 4$ & 3.4 & $16-27$ & $28 \cdot 9^{\star * \star *}$ & $7 \cdot 2$ & $14-41$ & $14 \cdot 3$ & $7 \cdot 5$ \\
\hline SAM:SAH & $5 \cdot 2$ & $1 \cdot 3$ & $4-8$ & $2 \cdot 9^{\star \star \star \star}$ & 0.8 & $2-4$ & $8 \cdot 9$ & 4.5 \\
\hline Adenosine $(\mu \mathrm{mol} / \mathrm{l})$ & 0.27 & 0.1 & $0.1-0.4$ & $0.39^{\star}$ & $0 \cdot 2$ & $0.17-0.83$ & 0.14 & 0.03 \\
\hline Total homocysteine $(\mu \mathrm{mol} / \mathrm{l})$ & $6 \cdot 4$ & $1 \cdot 3$ & $4 \cdot 3-9 \cdot 0$ & $5 \cdot 8^{\star \star}$ & 1 & $4 \cdot 0-5 \cdot 8$ & $7 \cdot 4$ & $1 \cdot 7$ \\
\hline Cystathionine $(\mu \mathrm{mol} / \mathrm{l})$ & 0.17 & 0.05 & $0.1-0.27$ & $0 \cdot 14^{\star * \star}$ & 0.06 & $0.04-0.2$ & 0.25 & 0.08 \\
\hline Cysteine $(\mu \mathrm{mol} / \mathrm{l})$ & 202 & 17 & $172-252$ & $163^{\star \star \star \star}$ & 15 & 133-189 & $199 \cdot 3$ & 15 \\
\hline Total glutathione $(\mu \mathrm{mol} / \mathrm{l})$ & $7 \cdot 6$ & $1 \cdot 4$ & $3 \cdot 8-9 \cdot 2$ & $4 \cdot 1^{\star \star \star \star}$ & 0.5 & $3 \cdot 3-5 \cdot 2$ & $6 \cdot 7$ & 1.6 \\
\hline GSSG (nmol/l) & 0.32 & 0.1 & $0.11-0.43$ & $0 \cdot 55^{\star \star \star \star}$ & 0.2 & $0.29-0.97$ & 0.25 & 0.05 \\
\hline Total glutathione:GSSG & $25 \cdot 5$ & $8 \cdot 9$ & $13-49$ & $8 \cdot 6^{\star * * *}$ & 3.5 & $4-11$ & $28 \cdot 7$ & $7 \cdot 1$ \\
\hline
\end{tabular}

SAM, S-adenosylmethionine; SAH, S-adenosylhomocysteine.

Mean value was significantly different from controls: ${ }^{*} P<0.05$, ${ }^{* *} P<0.01,{ }^{* \star *} P<0.002,{ }^{* * * *} P<0.001$. 
tissues. Consequently, any factor that inhibits PEMT activity (which is regulated by the concentration of PE, SAM, and $\mathrm{SAH}$ ) also modifies plasma and membrane FA composition. Three animal studies illustrate this effect. SAM:SAH fell from 5.6 to 0.3 in rat livers perfused with Hcy and adenosine, and the incorporation of labelled methionine into PC was decreased $>99 \%$ (Vance et al. 1997). Rats fed a folate-deficient diet for 6 weeks showed a significant reduction of plasma EPA $(P<0.01)$, DHA $(P<0.0001)$ and arachidonic acid $(P<0.01)$, whilst platelets had reduced EPA and DHA $(P<0.05)$ and increased arachidonic acid $(P<0 \cdot 01)$. Incorporation of $\left[{ }^{14} \mathrm{C}\right]$ arachidonic acid into platelets from folate-deficient rats was significantly greater than controls $(P<0 \cdot 01)$, and thrombinstimulated mobilisation of arachidonic acid was also greater $(P<0.002)$ (Durand et al. 1995). The PC:PE ratio, a marker of membrane fluidity, was lowest in rat livers between 24.00 hours and 02.00 hours when SAH was high, whereas maximum PC:PE correlated with one of the SAM:SAH maxima (Chagoya de Sanchez et al. 1991).

Of interest in the context of FA supplementation trials in schizophrenia is that plasma and tissue EPA was not depleted in Pemt -/- mice, suggesting that EPA transport may not be PEMT-dependent. If the PEMT pathway is compromised in schizophrenia this may explain why, in a DBPC trial, EPA supplementation $(2 \mathrm{~g} / \mathrm{d})$ was associated with improved scores on the Positive and Negative Syndrome Scale, whilst DHA treatment was ineffective (Peet et al. 2000).

\section{Choline deficiency}

Choline plays a dual role in phospholipid metabolism: directly as a precursor of PC in the Kennedy pathway; indirectly as a precursor of betaine which produces methionine, and hence SAM, via BHMT. Choline-derived SAM can then be used to synthesise PC via the PEMT pathway (DeLong et al. 2002). Choline deficiency therefore impacts on both major pathways of PC synthesis.

Dietary choline makes a significant contribution to methylation status via BHMT, which has been overlooked in many studies examining diet and Hcy levels (Zeisel et al. 2003). Although this pathway is not present in the brain, the effects of oral SAM on mood demonstrate that it crosses the blood-brain barrier; hence, choline-derived SAM also impacts on cerebral methylation.

High PLA2 activity is associated with schizophrenia (Ross et al. 1997; Glen et al. 2003a). Interestingly, choline deficiency increases PLA2 activity; a study in mice fed a choline-deficient diet found PLA2 activity increased by $50 \%$ after 1 week and by $300 \%$ after 4 weeks (Singh et al. 1990).

Highly elevated skeletal muscle-derived serum creatine phosphokinase $\left(\mathrm{CPK}_{\mathrm{MM}}\right)$ is frequently found in schizophrenic and bipolar patients during episodes of acute psychosis (Manor et al. 1998). It was assumed that this was due to muscle damage caused by tension or agitation during psychosis. However, many patients are hypoactive at such times, and no evidence of myoglobinuria or pigmenturia accompanying CPKaemia was found in a study of twentyfive acute psychotic patients, which might be expected if muscle damage were the cause (Hermesh et al. 2001). Interestingly, in three of four human volunteers fed a choline-deficient diet for up to $42 \mathrm{~d}, \mathrm{CPK}_{\mathrm{MM}}$ levels were increased up to 66-fold $(P<0 \cdot 01)$. In addition, mouse myocytes grown in a choline-deficient medium leaked 3.5fold more $\mathrm{CPK}_{\mathrm{MM}}$ than controls $(P<0.01)$; PC concentrations were $43 \%$ of control levels, as were intracellular choline, phosphocholine, and glycerophosphocholine. The deficient cells had greater osmotic fragility, resulting in increased $\mathrm{CPK}_{\mathrm{MM}}$ leakage (da Costa et al. 2004). These findings suggest a role for choline or PC deficiency in a previously unexplained physiological symptom of psychosis.

Human hippocampal choline, measured by proton magnetic resonance spectroscopy, decreased in major depressive episodes and normalised in parallel with treatment response to electroconvulsive therapy (Ende et al. 2000). Choline increase was also found in electroconvulsivetherapy-treated rats (Sartorius et al. 2003).

\section{Membrane fluidity}

Much has been written about the influence of LCPUFA on membrane fluidity and hence receptor function; however, the degree of phospholipid methylation (PLM) is also a significant determinant of fluidity. Whilst diet influences membrane composition in the long term, PLM provides short-term local regulation of phospholipid packing density by increasing the spacing between head groups (Hirata \& Axelrod, 1980; Zhao et al. 2001).

PLM plays an important role in transduction of receptormediated signals through cell membranes. As phospholipids are successively methylated, they are translocated from inside the cell membrane to the exterior (Hirata \& Axelrod, 1980). For example, MET313 of the dopamine D4 receptor is on the inner surface of the cell membrane and supplies a methyl group for local methylation of PE to PC in response to dopamine stimulation. 5-MTHF is then required for the re-methylation of $\mathrm{D} 4$ receptor $_{\mathrm{Hcy}}$ to $\mathrm{D} 4$ receptor $_{\mathrm{Met}}$. In vitro studies showed that $14 \mathrm{~d}$ after 5-MTHF supply was compromised, basal PLM was reduced, whilst dopaminestimulated PLM increased by $200 \%$. However, after 28 and $42 \mathrm{~d}$ basal PLM recovered and dopamine-stimulated PLM fell below initial levels (Zhao et al. 2001). The authors suggest that reduced basal PLM may alter the D4 receptor membrane environment, increasing agonist responsiveness. A study examining PLM in lymphocytes of male schizophrenics aged 27-70 years found basal PLM reduced by $3 \cdot 5$-fold compared with controls, indicating a profound defect in this pathway. Furthermore, dopamine stimulated methylation by $30 \%$ in controls, v. $165 \%$ in patients (Deth et al. 1996).

\section{Niacin skin flush test}

A reduced skin-flush reaction in response to topical niacin has been replicated in forty-one schizophrenic populations worldwide (I Glen, personal communication; Maclean et al. 2003).

As Fig. 3 illustrates, niacin stimulates the synthesis of newly derived PC from arachidonic acid-rich PE via the 
PEMT pathway, and activates PLA2 to release free arachidonic acid. Prostaglandin (PG)D synthase, cyclooxgenase-1 and cyclo-oxgenase-2 then produce PGD2 from free arachidonic acid. PGD2 acts upon capillary endothelial cells causing vasodilation, producing the skin-flush response (Bennett \& Horrobin, 2003).

Although the increased PLA2 activity found in schizophrenia implies an increased flush response, it is hypothesised that increased activity leads to desensitisation after over-stimulation of the pathway, or that reduced membrane arachidonic acid reduces the substrate available for PGD synthase.

Alternatively, since low cellular methylation potential reduces PEMT activity, this pathway may be disrupted by inadequate formation of newly derived PC from PE due to high SAH and/or low SAM.

\section{Sex differences and effects of diet}

In mice fed a high-fat high-cholesterol diet, $\mathrm{PC}$ production increased to support hepatic export of bile and lipoprotein. Cytidydyl transferase activity, the rate-limiting enzyme of the Kennedy pathway, was unchanged; hence the extra PC was produced via the PEMT pathway (Drouva et al. 1987; Noga \& Vance, 2003). Some consequences of a high-fat high-cholesterol diet, therefore, are an increased methylation demand, and higher SAH and Hcy production.

Sex differences exist in the phospholipid metabolism of mice; hepatic PEMT activity in females is double that in males, whilst males have more cytidydyl transferase activity. In rats, oestrogen stimulated PE methylation in pituitary membranes, and elevated plasma oestradiol was associated with increased PEMT activity (Drouva et al. 1987). Oestrogen also stimulates the desaturases needed for the production of LCPUFA from their parent EFA; thus females may be better equipped to both synthesise and transport LCPUFA to the periphery.

Interestingly, puerperal psychosis has been linked to oestrogen levels. Psychosis risk is twenty-two times higher in the first month post-partum than pre-pregnancy. At term, serum oestradiol is very high and of placental origin; the concentration falls precipitously within a few days of parturition and recovery of ovarian production can be slow (Ahokas et al. 2000). In some patients, further psychotic episodes occur pre-menstrually (Brockington \& Meakin, 1994).

\section{Lithium and valproate}

Both Li and valproate are effective mood stabilisers in BPD, despite their structural dissimilarity and differing biochemical effects. A study was conducted in yeast cells to determine common drug targets. Both drugs increased the rate of PC synthesis, and decreased phosphatidylinositol synthesis. The authors suggest that restoration of the phosphatidylinositol:PC ratio required for secretory vesicle formation is therapeutic (Ding \& Greenberg, 2003). If cellular methylation potential is disturbed in BPD, reduced PEMT activity would also disturb the phosphatidylinositol:PC ratio; restoration of normal methylation might therefore stabilise mood.

Finally, significantly reduced PC methylation was found in Li-responsive patients. Ex vivo evidence demonstrated that Li increased PLM in responders, but not non-responders (Kingsbury \& Garver, 1998).

\section{Oxidative stress}

Increased oxidative stress may be a causative factor in the phospholipid disturbances found in schizophrenic and bipolar patients. The brain is under higher oxidative stress than other organs since it produces high reactive oxygen species levels and enzymic antioxidant defence is relatively poor. LCPUFA-rich plasma membranes are the preferred target for reactive oxygen species-mediated injury, hence neural membrane lipids are especially sensitive to peroxidation.

Reduced membrane LCPUFA and increased plasma lipid peroxides as measured by thiobarbituric acid-reactive substances have been reported in both medicated and never-medicated schizophrenics (Arvindakshan et al. 2003), and in first-episode psychotic patients (Khan et al. 2002). Furthermore, analysis of expired ethane levels, a specific marker of $n-3$ fatty acid peroxidation, showed significantly greater median levels in schizophrenics than controls (16 (50\% interquartile range 0.6) v. 0.2 (50\% interquartile range 0.4) parts per billion); the difference was still significant between control and schizophrenic smokers (Glen et al. 2003b).

\section{Glutathione}

GSH is constantly exported from the liver, but plasma levels are kept relatively low by the activity of the cell surface enzyme $\gamma$-glutamyl transpeptidase, which degrades GSH to cys-gly and then cysteine. Since the CNS lacks the full trans-sulfuration pathway, this process is essential for transporting the building blocks of GSH to the CNS. Thus, hepatic thiol status is directly related to CNS antioxidant defence.

In a study of twenty-one drug-naive, and five drug-free schizophrenics, CSF GSH was significantly reduced by $27 \%(P<0.05)$ compared with controls, whereas levels of dopamine and serotonin metabolites were similar.

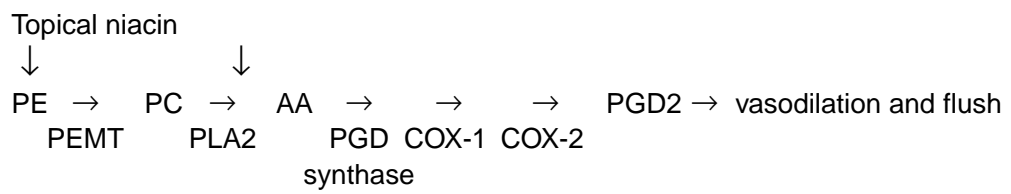

Fig. 3. The biochemical sequence of the skin-flush response. PE, phosphatidylethanolamine; PC, phosphatidylcholine; AA, arachidonic acid; PG, prostaglandin; PEMT, phosphatidylethanolamine methyltransferase; PLA2, phospholipase A2; COX, cyclo-oxygenase. 
Furthermore, when magnetic resonance spectroscopy was used to determine GSH levels in the pre-frontal cortex of fourteen male schizophrenic in-patients, five previously treated with neuroleptics, five drug-naive, and four drugfree for at least 6 months, GSH was reduced by $52 \%$ compared with controls $(P=0.0012)$ (Do et al. 2000). Since dopamine metabolism contributes to oxidative stress, the authors suggest that a GSH deficit would result in degenerative processes surrounding dopaminergic terminals. Also, since GSH potentiates the NMDA receptor response to glutamate, low GSH may result in hypoactivation of NMDA receptors. A follow-up study investigated the effects of dopamine in cultured cortical neurons with low GSH; dopamine decreased GSH by $40 \%$, and a $24 \mathrm{~h}$ application of dopamine significantly decreased neuronal processes (Grima et al. 2003).

The previously cited study in autism demonstrated that disruption of the one-carbon cycle can be associated with diminished GSH and hence reduced antioxidant capacity (James et al. 2004). It is therefore feasible that lipid peroxidation in schizophrenia could be mediated by low GSH, resulting from one-carbon cycle disruption. Conversely, oxidative stress impinges directly on the one-carbon cycle, since the cobalamin-MS complex is easily oxidised; methionine adenosyltransferase and BHMT are also sensitive to oxidation. Consequently, any endogenous or exogenous insult that increases cellular oxidative stress would impinge on both phospholipid and methylation status.

\section{Methylation and epigenetics}

\section{Epigenetic modification of gene expression}

Epigenetics is defined as the modification of gene expression with no alteration in DNA base sequence. Methylation is one of several known epigenetic mechanisms that facilitate short-term adaptation of genomic DNA to the local environment. DNA methylation occurs when a methyl group is transferred from SAM to cytosine residues in the dinucleotide sequence $\mathrm{CpG}$. Dense methylation of $\mathrm{CpG}$ 'islands' found predominantly in the gene promoter region is generally associated with irreversible gene silencing, whilst the more common partial methylation is associated with genes that can be reactivated. Methylation silences gene expression by two different mechanisms. Methylation of transcription factor binding sites directly inhibits transcription without necessarily altering chromatin structure. Alternatively, methylated DNA binding proteins are recruited to a densely methylated region and target histone deacetylases to the chromatin, resulting in histone deacetylation and chromatin inactivation (Abdolmaleky et al. 2003; Weaver et al. 2005).

Valproate, a drug commonly used for treating epilepsy, mood disorders and schizophrenia, is an histone deacetylases inhibitor which induced DNA demethylation (Detich et al. 2003) and increased gene expression in vitro (Chen et al. 2002), and re-activated cerebral genes in vivo whose activity had been down regulated by supplementing mice with methionine (Tremolizzo et al. 2002).
Dysregulation of the methylation cycle may have different effects on gene methylation and expression depending on the tissue, the specific gene and region of the gene involved. Hence, it is difficult to predict the effect that dietary methyl source insufficiency (or excess), and consequent DNA methylation dysregulation, will have on individual gene expression. However, the finding that the expression of key genes associated with psychiatric illnesses can be manipulated by diet (see p. 129 of proof) suggests that this is an area worthy of more research.

\section{Epigenetics and schizophrenia}

Despite a decade of genetic research, no DNA mutations have yet been identified that suggest a cause of, or genetic predisposition to, the development of psychiatric illness. The concordance rate for psychiatric phenotypes in monozygotic twins is well below 100\%: 41-65\% in schizophrenia; $62-79 \%$ in BPD; $31 \%$ for males and $48 \%$ for females in major depression.

However, preliminary findings suggest that epigenetic DNA modifications resulting in altered gene expression may underlie the phenotypic differences between monozygotic twins. A study comparing the content and distribution of methylated DNA and histone acetylation in peripheral lymphocytes between monozygotic twins aged 3-74 years found that young twins were epigenetically indistinguishable, whilst older twins exhibited significant differences affecting their gene expression portrait (Fraga et al. 2005). In a study comparing the $5^{\prime}$-regulatory regions of the dopamine D2 receptor gene in two sets of monozygotic twins (aged 24 years), one concordant and one discordant for schizophrenia, the patient from the discordant pair was found to be epigenetically 'closer' to the concordant pair than to his unaffected twin (Petronis et al. 2003).

\section{Reelin and glutamic acid decarboxylase 67}

Reelin is a glycoprotein that regulates neuronal migration in the developing embryonic brain, and is also expressed in the adult brain. In adults, reelin is secreted from $\gamma$-aminobutyric acid (GABA)ergic interneurons into the extra-cellular matrix (Carboni et al. 2004; Fatemi et al. 2005), and is currently known to bind to two apo receptors, ApoER2 and VLDL receptor, and to the integrin receptor. Reelin potently enhances synaptic transmission, and strengthens betweenneuron synaptic contacts, believed to be one of the processes underlying memory. Glutamic acid decarboxylase (GAD) is the rate-limiting enzyme in the conversion of glutamate to GABA, and hence regulates glutamate and GABA levels in the brain. Deficits in brain reelin levels affect memory processing, learning, synaptic organisation and cognition (Fatemi et al. 2005).

In all post mortem schizophrenic brains examined to date, a reduction in reelin and $\mathrm{GAD}_{67}$ gene expression and about $50 \%$ reduction in reelin protein levels have been found in all brain areas examined, including multiple cortical regions, hippocampi and cerebella (Impagnatiello et al. 1998; Guidotti et al. 2000). Down regulation of reelin and $\mathrm{GAD}_{67}$ was also found in the brains of bipolar patients, and a non-significant trend for 
reduced reelin was observed in depression. Analysis of post mortem markers in pre-frontal cortices showed that $\mathrm{GAD}_{67}$ protein was the most useful marker for discriminating between schizophrenia, BPD and depression. Significant reductions in GAD and reelin were also observed in autistic subjects; the reelin deficit was greater than in schizophrenia and BPD (Fatemi et al. 2005).

Although little is known about the regulation of reelin expression in mature neurons, incorporation of the methylation inhibitor 5-axa-deoxycytidine activated reelin expression $>50$-fold in vitro, whilst methylation of the reelin promoter silenced expression. Furthermore, the histone deacetylase inhibitors trichostatin $\mathrm{A}$ and valproate significantly increased reelin mRNA levels (Chen et al. 2002).

\section{Heterozygous reeler mice}

An animal model of reelin insufficiency, the heterozygous reeler mouse (HRM), exhibits some of the neuropathology detected in schizophrenia including: decreased extracellular reelin, with a marked decrease in dendritic spine expression density in pyramidal neurons of the cortex and hippocampus, and decreased cortical thickness; decreased $\mathrm{GAD}_{67}$ expression in frontal cortex, and an alteration in the mesolimbic dopamine system, but not the nigro-striatal system; a deficit in sensorimotor gating or pre-pulse inhibition of startle, and an exaggerated response to fear; significantly poorer performance on an olfactory discrimination task. The similarities between this model and autism have also been noted (Carboni et al. 2004; Fatemi et al. 2005).

Dizocilpine is a non-competitive NMDA receptor antagonist. Such antagonists cause cognitive impairment and psychotic symptoms in normal human subjects indistinguishable from those observed in schizophrenia, and exacerbate psychosis in schizophrenics. A recent study demonstrated that HRM have an increased susceptibility to dizocilpine-induced amnesia compared with wild-type mice (WTM). Furthermore, the infusion of $\left[{ }^{13} \mathrm{C}\right]$ glucose into WTM and HRM demonstrated that although GABA levels in the frontal cortex, hippocampus and striatum were similar in WTM and HRM, the $\left[{ }^{13} \mathrm{C}\right] \mathrm{GABA}$ conversion index from $\left[{ }^{13} \mathrm{C}\right]$ glutamate was decreased in HRM by $>30 \%$ (Carboni et al. 2004). This study suggests that the reduced reelin secretion observed in schizophrenic brains substantially reduces GABA turnover. GABA deficiency affects multiple functions including locomotor activity, learning, reproduction, and circadian rhythms. Low levels of CSF and plasma GABA have been reported in BPD, schizophrenia and depression. Furthermore, decreased GAD activity suggests that the reported increases in blood and CSF of glutamate and glutamine in schizophrenia, depression and autism are due to an accumulation of precursors (Fatemi et al. 2005).

\section{DNA methyltransferase-1 and schizophrenia}

DNA methyltransferase (Dnmt)-1 is responsible for the maintenance methylation of hemi-methylated DNA postreplication. In vitro evidence suggests that Dnmt-1 expression is regulated by negative feedback whereby methylation of a regulatory element of Dnmt-1 is sensitive to cellular methylation capacity. An eight-fold increase in Dnmt-1 mRNA induction was observed when cells were challenged by 5-azacytidine, a methylation inhibitor. Moreover, rodents fed methionine-deficient diets exhibited both global hypomethylation and increased Dnmt-1 expression and activity (Slack et al. 1999).

A recent post mortem study of schizophrenic brains found that the number of Dnmt-1 mRNA-positive neurons was inversely correlated with the number of reelin mRNApositive neurons in cortical GABAergic interneurons, independent of neuroleptic type. Dnmt-1 activity was significantly greater in schizophrenic than in non-psychiatric controls. Furthermore, one patient with no history of neuroleptic use had results well within the range of medicated patients (Veldic et al. 2004a). Other groups using different patient cohorts have confirmed these findings. A follow-up study found that Dnmt-1 expression was increased in psychotic patients taking valproate alone $(n 4)$ or anti-psychotics alone $(n 15)$ but not in those taking both (n 9) (Veldic et al. 2004b).

In an in vitro study of mouse embryonic cortical neurons, Dnmt-1 knockdown blocked the increased methylation of the reelin promoter and down regulation of reelin and $\mathrm{GAD}_{67}$ mRNA expression induced by methionine administration. This study supports the hypothesis that the reduction of reelin and $\mathrm{GAD}_{67}$ mRNA found in post mortem schizophrenic brains is due to hypermethylation of the respective promoters by Dnmt-1 (Noh et al. 2004). Furthermore, in the HRM model of schizophrenic neuropathologies, the biochemical (reelin promoter methylation) and behavioural (pre-pulse inhibition of startle and social interaction deficits) alterations elicited by methionine administration were normalised by valproate (Tremolizzo et al. 2005).

No explanation for increased Dnmt-1 expression in schizophrenia has been suggested in the literature. Clearly excess dietary methionine is unlikely to be the cause; however, the finding of elevated CSF methionine in schizophrenics cited earlier (Regland et al. 2004) may be relevant if confirmed in further studies. Conversely, animal studies demonstrate that methyl-deficient diets also increase Dnmt-1 activity (Christman et al. 1993; Slack et al. 1999). Rats fed a methyl-deficient diet for 1-4 weeks developed alterations in gene expression; RNA and Dnmt activity increased 2-3-fold. At 1-2 weeks after normal diet restoration, gene expression and methyltransferase activity was normalised. Thus, it appears that the response of Dnmt-1 to dietary methyl-group sources is biphasic; both dietary excess and deficiency increase enzyme activity and alter gene expression in animals. However, whether methyl-group deficiency reduces reelin expression has not yet been tested.

\section{Diet and gene expression}

Whilst dietary methyl donor deficiency has been the subject of many studies, the effects of excess SAM precursor supplementation are less well known. Three studies in mice demonstrate the effects of such supplementation in pregnant mice. 
Epigenetic variation in the expression of the agouti gene is evident in the coat colour of mice with the viable yellow allele $\left(\mathrm{A}^{\mathrm{vy}}\right)$ of agouti. The $\mathrm{A}^{\mathrm{vy}}$ gene is expressed to different degrees in genetically identical mice depending on the degree of gene methylation. The failure to methylate and suppress the $\mathrm{A}^{\mathrm{vy}}$ gene during development leads to agouti expression in all tissues, as opposed to cyclic expression limited to hair follicles. Epigenetic variations in $\mathrm{A}^{\mathrm{vy}}$ expression produce phenotypes ranging from pure yellow through slightly mottled, mottled, heavily mottled to the normal (pseudoagouti) mouse. The pure yellow phenotype is obese, and has an increased risk of diabetes and cancer.

Two levels of SAM precursor supplements were compared with a control diet in pregnant $\mathrm{A}^{\mathrm{vy}} / \mathrm{a}$ mice. The mid-range diet contained choline, betaine and folic acid (each $5 \mathrm{~g} / \mathrm{kg}$ ), and $0.5 \mathrm{~g}$ cobalamin $/ \mathrm{kg}$. The high-level diet contained three times the level of choline, betaine, folate and cobalamin plus $7.7 \mathrm{~g}$ L-methionine $/ \mathrm{kg}$ and $150 \mathrm{mg}$ $\mathrm{Zn} / \mathrm{kg}$. Although a range of coat colour variation remained in the offspring, the distribution was significantly shifted towards the normal coat colour with increasing supplement levels $(P<0 \cdot 001)$ (Cooney et al. 2002).

In a second study, a/a females were supplemented with folic acid, cobalamin, choline chloride and anhydrous betaine, and mated with $\mathrm{A}^{\mathrm{vy}} / \mathrm{a}$ males. Once again, coat colour distribution in $\mathrm{A}^{\mathrm{vy}} / \mathrm{a}$ offspring was significantly shifted towards the pseudoagouti phenotype compared with controls $(P=0.008)$. The highly significant effect of supplementation on coat colour vanished when $A^{\text {vy }}$ methylation was included in the model, indicating that the $\mathrm{A}^{\mathrm{vy}} \mathrm{CpG}$ methylation mediates the effect of supplementation on coat colour. Furthermore, $\mathrm{A}^{\mathrm{vy}}$ gene methylation from the tail tip was increased at all seven examined sites, and the average percentage methylation was highly correlated with samples from the liver, kidney and brain (Waterland \& Jirtle, 2003).

In the third study, the effect of maternal high-dose folinic acid supplementation was examined in folate-binding protein-1 knock-out mice. Of note was that supplementation caused global DNA hypomethylation in the folate-binding protein-1 $+/+$ (i.e. normal) embryos compared with controls. The authors proposed that folinic acid inhibited GNMT, leading to alterations in the levels of SAM and SAH. SAM:SAH was increased in the liver but reduced in the brain (Finnell et al. 2002).

A fourth study, in $60 \mathrm{~d}$ old male WTM and HRM, examined the effects of L-methionine supplementation $(6.6 \mathrm{mmol} / \mathrm{kg}$ twice daily for $15 \mathrm{~d})$. The treatment down regulated the expression of both reelin and $\mathrm{GAD}_{67}$ mRNA by about $40 \%$ in both WTM and HRM (despite the lower reelin production in this strain) compared with vehicletreated mice. Similar treatment with glycine produced no effects. Furthermore, the down regulation was associated with a significant increase (about 2 -fold) in the number of methylated cytosines in the reelin promoter region, and the mean of cytosine residues correlated with levels of reelin mRNA $(R-0.67 ; P<0.001)$. Valproate administration normalised the induced down regulation of reelin and $\mathrm{GAD}_{67}$ mRNA in both WTM and HRM (Tremolizzo et al. 2002).
Although the first two of these studies imply that maternal supplementation of methylating factors improves offspring health, the third study suggests that such interference with epigenetic gene-regulatory mechanisms may have unintended consequences. The gene expression pattern of multiple genes may be altered, in a positive or negative direction, and if such changes occur in the gametes, they may be heritable. Last, the fourth study demonstrates that exposure to excess SAM precursors postnatally can reduce reelin and $\mathrm{GAD}_{67}$ production by increasing gene promoter methylation.

\section{Folate supplements in pregnancy}

In 1982, the Spanish NHS recommended early folate treatment for all women intending to conceive to prevent neural tube defects (NTD). In fact, physicians began prescribing multivitamins and folate some years earlier. In $19763 \%$ of pregnant women received multivitamins, rising to $10 \%$ in $1977,35 \%$ in 1982 and $55 \%$ in 1986. Two studies found that the MTHF reductase TT genotype frequency in Spain rose from $13 \%$ to $26 \%$ over the same period, hypothesised to be a direct result of folate supplementation (Munoz-Moran et al. 1998). The authors suggest that the increase in TT genotype frequency after folate supplementation was because extra folate prevented the spontaneous abortions that occur fairly frequently in TT homozygous fetuses under normal conditions.

What might be the short- and long-term health effects on infants programmed in utero to be dependent on a highfolate diet, of a substantial drop in folate intake postnatally? Other less well-studied polymorphisms may have increased in frequency and more subtle effects might be found at the cellular level, such as reduced folate-binding protein due to folate 'flooding' in utero. Indeed, isolated cells can show a permanent change in function due to fetal programming, for example, pancreatic islets from animals born to proteindeficient mothers release less insulin (Rees et al. 2000; Petry et al. 2001; Gluckman \& Hanson, 2005).

In 1991, the Medical Research Council published a study examining folic acid supplementation in pregnant women at high risk of an NTD pregnancy (Anonymous, 1991). The double-blind trial compared $4 \mathrm{mg}$ folate with supplements of seven other vitamins, combined folate and vitamins or neither, and showed a $72 \%$ protective effect of folate against an NTD birth. However, the authors noted the inability of the study to detect rare or slight adverse effects.

Only one study examined the effects of multivitamins containing $800 \mu \mathrm{g}$ folate in women not known to be at risk of an NTD pregnancy. Although the NTD rate was reduced, post hoc analysis appeared to indicate increased fertility and a significantly increased risk of early abortion in supplemented women $(P<0.04)$ (Hook \& Czeizel, 1997).

Following the Medical Research Council study, all women intending to conceive in the UK and the USA are encouraged to take folic acid supplements and, since January 1998, all grain products in the USA have been fortified with $140 \mu \mathrm{g}$ folic acid/100 g grain product. A study examining the effects of folate fortification noted that fortified foods typically contain $160-175 \%$ of the labelled content. In addition, many 'super-fortified' breakfast 
cereals, labelled as containing $400 \mu \mathrm{g} / 30 \mathrm{~g}$ serving are typically consumed in $60 \mathrm{~g}$ portions; thus an individual could easily consume more than the safe upper limit of folate $(1 \mathrm{mg} / \mathrm{d})$ in one serving of cereal (Quinlivan \& Gregory, 2003). The authors estimate that $>5 \%$ of adults consume $>1 \mathrm{mg}$ folate/d, and point out that an intake $>200 \mu \mathrm{g}$ exceeds the capacity of the body to convert it to 5-MTHF, leading to unmetabolised folic acid in the bloodstream. Since this is readily absorbed and retained by cells, without the need for conversion to THF by MS, this may disturb cellular folate homeostasis.

Despite fortification, US women intending to conceive are still encouraged to take folate. Consequently, a woman consuming a typical high-protein US diet may have a more than adequate intake of methionine, choline and cobalamin, combined with a high folate intake derived from her diet, fortification, multivitamin and folate supplements.

\section{Excess folate, reelin and autism?}

Data collected in California showed that new cases of level 1 DSM-IV autism from 1971 to 1980 were consistent at 1-200 annually. Since 1980, the number of new cases annually has increased dramatically and continues to rise, a situation that is repeated across the USA (Figs. 4 and 5). Although the UK incidence of autism also appears to have increased, the lack of a central database makes verification difficult.

A post mortem study found reductions of $43-44 \%$ in reelin 410 and its isoforms in autistic cerebella (Fatemi et al. 2001). Moreover, reelin was recently found to be the only possible source of the unusual peptides found in the urine of autistic and schizophrenic patients (Reichelt et al. 1981). A polymorphism in the reelin gene that reduces reelin production by $25 \%$ was recently identified in $20 \%$ of a group of US autistic subjects (Persico et al. 2001), but was not replicated in other studies.

Clearly, an 8- to 10-fold increase in autism cases in 20 years must be due to one or more environmental factors. Viral infections, either in utero or during infancy, and multiple vaccinations at sensitive times for brain development, are suggested triggers. Viral infection mid-gestation reduced reelin levels in the brains of neonatal mice (Fatemi et al. 2005). Although multiple vaccinations ceased in Japan a decade ago with no reduction in autism incidence, many parents report an adverse reaction to vaccination shortly before a dramatic regression through developmental milestones before diagnosis. Thimerosal, a Hg-based preservative used in vaccines for many years, has recently been banned in the USA after suggestions that $\mathrm{Hg}$ may be the environmental trigger. Autistic children have a reduced ability to excrete $\mathrm{Hg}$, possibly due to reduced functioning of the trans-sulfuration pathway. It is too early to tell whether the Thimerosal ban will have a significant effect on autism incidence.

A possible connection between infections and/or vaccinations and autism is suggested by the fact that immune stimulation draws on the folate pool for clonal expansion. Thus, immune stimulation due to infection(s) or multiple vaccinations could further reduce an insufficient folate pool to a critical level, reducing the cellular methylation potential and up regulating Dnmt-1. The effect of folate deficiency and increased Dnmt-1 activity in carriers of the RELN polymorphism, or in children 'programmed' in utero to be dependent on a high-folate diet, may be to further reduce reelin production and GABA turnover to levels too low to sustain normal neuronal metabolism at a critical time for brain development.

It is notable that the two periods of selective apoptosis of neuronal synapses in the brain coincide with the appearance of symptoms of autism (at 2-3 years) and schizophrenia (during adolescence). Perhaps we will witness a transition from the currently increasing rates of schizophrenia and BPD, to an 'explosion' as this generation of highly pre-natally supplemented children reach adolescence.

\section{Folate supplements and gene expression}

Dietary manipulation can restore normal gene expression following disruption caused by inadequate methylation. A study in uraemic patients with hyperhomocysteinaemia demonstrated the effects of folate supplementation on gene

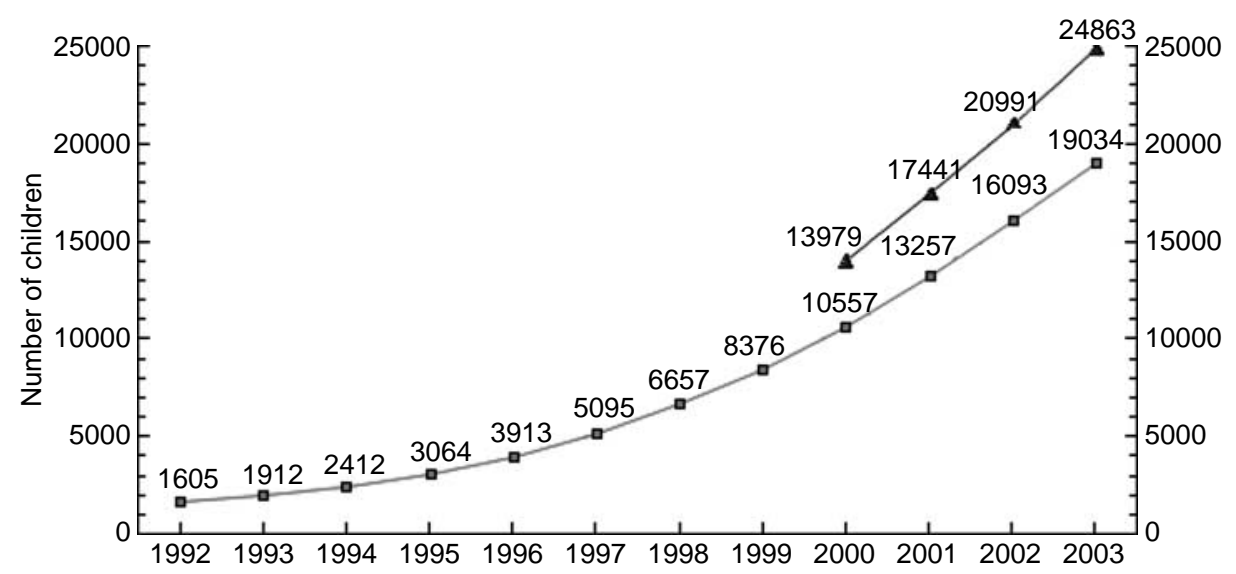

Fig. 4. The incidence of autism in California from 1992 to 2003 in ages 6-22 years ( $\square$ ) and ages 3-22 years ( $\Delta$ ) (no. of cases in the US school years 1992-2003). (Reproduced with permission from www.fightingautism.org; data are from www.ideadata.org and www.cdc.gov/nchs/) 


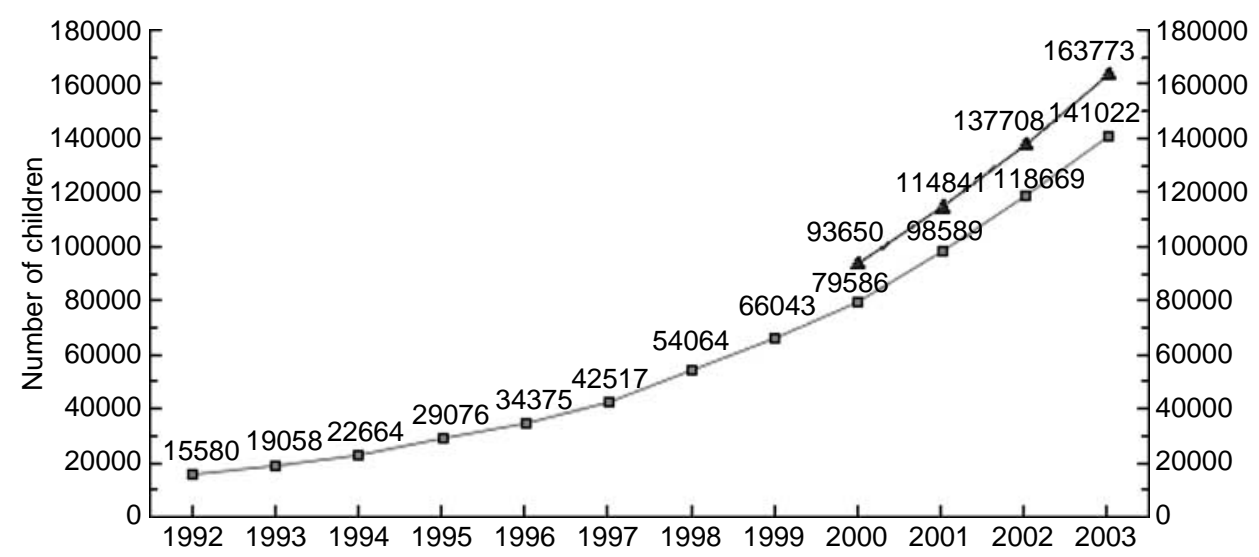

Fig. 5. The incidence of autism in the USA and outlying areas from 1992 to 2003 in ages 6-22 years ( $\square$ ) and ages $3-22$ years ( $\Delta$ ) (no. of cases in the US school years 1992-2003). (Reproduced with permission from www.fightingautism.org; data are from www.ideadata.org and www.cdc.gov/nchs/)

expression in vivo. The expression of two tightly linked genes, H19 and IGF2, is inversely regulated by epigenetic mechanisms including methylation. After 8 weeks of folate washout, patients with plasma total Hcy levels $>62 \mu \mathrm{mol} / 1$ were found to have biallelic expression of $\mathrm{H} 19$ in peripheral mononuclear cells, whereas expression in controls and in patients with lower plasma total Hcy was monoallelic. Biallelic expression of $\mathrm{H} 19$ was associated with negligible expression of IGF2. Treatment with $15 \mathrm{mg}$ methylfolate/d reduced plasma total Hcy levels, restored monoallelic expression of H19, and significantly increased IGF2 expression (Ingrosso et al. 2003).

\section{Discussion and conclusion}

The evidence presented demonstrates that biomarkers of disturbed one-carbon metabolism are a common feature of psychiatric illness, but does not establish a causal relationship. One-carbon dysregulation could be a cause or a consequence of psychiatric illness, or an epiphenomenon. Illness-induced poor appetite or diet could create nutrient deficiencies causing biochemical dysregulation. However, if dysregulation were solely a by-product of psychiatric illness, with no causal relationship, then nutrient supplements would be expected to restore normal one-carbon metabolism but not to impact on psychiatric symptoms, yet clinical trials demonstrate significant symptom improvements.

A major problem in the study of biochemical imbalances in psychiatric patients is the lack of access to brain tissue in vivo; peripheral cell and plasma metabolites may not replicate the situation in the brain. The findings that plasma folate correlates with CSF folate in human subjects, and that MS activity is closely correlated with the cerebral SAM:SAH ratio in pigs, are promising but inconclusive. However, a number of clinical trials have demonstrated that alleviating deficiencies of various methylating factors has a significant effect on psychiatric symptoms, supporting the hypothesis that disturbed plasma levels of one-carbon metabolites reflect disturbed cerebral methyl metabolism, which presents as psychiatric symptoms. The unanswered question of whether plasma or peripheral cell metabolites replicate the situation in the brain may be of academic interest, but should not delay further studies exploring the association between methylation metabolites and clinical symptoms, both before and after nutrient supplementation.

The SAM:SAH ratio has not yet been determined in schizophrenia, BPD and depression, but if disturbed, the downstream disruption of methyltransferase activities could account for much disease-associated pathology, including altered gene expression, membrane fatty acid composition, memory and cognitive function, and sleep patterns.

Novel findings from the field of epigenetics provide a plausible link between poor methylation status and psychiatric symptoms. The expression of RELN and GAD genes are reduced in depressed, bipolar, schizophrenic and autistic brains, and GAD protein levels can differentiate between the conditions. In schizophrenic brains, reduced reelin is associated with increased Dnmt-1 expression and activity. Both low and high cellular methylation status increases Dnmt-1 expression, but whether either is causal in schizophrenia has not been determined. Dietary manipulation altered the expression of other methyl-sensitive genes in uraemic patients, and RELN and GAD expression have responded to nutrient supplementation in mice.

The prevalence of low serum folate and/or cobalamin levels, and high plasma or serum total Hcy, in the psychiatric population strongly suggests that all patients should be appropriately tested and treated, before pharmacological therapy. For a sub-group of depressed patients such treatment might be sufficient to restore health, and for others it may improve their response to anti-depressants. However, optimum supplementation levels must be determined, since over-methylation is also detrimental. The high rate of CVD in the schizophrenic population confirms the importance of monitoring plasma or serum total Hcy levels, and Hcylowering nutrient therapy has improved psychiatric symptoms in this patient group. Given the proven benefits and lack of side effects of SAM in treating depression, it is surprising that SAM is not part of current treatment protocols.

In view of the enormous costs of psychiatric illness, both personal and social, and the detrimental long-term effects of neuroleptic medications, further research is urgently needed to elucidate the role of nutrients in the prevention and treatment of psychiatric illness. 


\section{References}

Abdolmaleky HM, Smith CL, Faraone SV, Shafa R, Stone W, Glatt SJ \& Tsuang MT (2003) Methylomics in psychiatry: modulation of gene-environment interactions may be through DNA methylation. American Journal of Medical Genetics 127B, $51-59$.

Ahokas A, Aito M \& Turianen S (2000) Association between oestradiol and puerperal psychosis. Acta Psychiatrica Scandinavica 101, 167-169.

Alpert JE \& Fava M (1997) Nutrition and depression: the role of folate. Nutrition Reviews 55, 145-149.

Andreoli VM \& Maffei F (1975) Blood-levels of S-adenosylmethionine in schizophrenia. Lancet 306, 922.

Anonymous (1991) Prevention of neural tube defects: results of the Medical Research Council Vitamin Study. Lancet 338, $131-137$.

Antun FT, Burnett GB, Cooper AJ, Daly RJ, Smythies JR \& Zealley AK (1971) The effects of L-methionine (without MAOI) in schizophrenia. Journal of Psychiatric Research 8, 63-71.

Applebaum J, Shimon H, Sela B-A, Belmaker RH \& Levaine J (2004) Homocysteine levels in newly admitted schizophrenic patients. Journal of Psychiatric Research 38, 413-416.

Arinami T, Yamada N, Yamakawa-Kobayashi K, Hamaguchi H \& Toru M (1997) Methylenetetrahydrofolate reductase variant and schizophrenia/depression. American Journal of Medical Genetics (Neuropsychiatric Genetics) 74, 526-528.

Arvindakshan M, Sitasawad S, Debsikdar V, Ghate M, Evans D, Horrobin DF, Bennett C, Ranjekar PK \& Mahadik SP (2003) Essential polyunsaturated fatty acid and lipid peroxide levels in never-medicated and medicated schizophrenic patients. Biological Psychiatry 53, 56-64.

Bennett CN \& Horrobin DF (2003) Impaired niacin flushing in schizophrenia: possible biological mechanisms. Schizophrenia Research 60, Suppl. 1, 98.

Bentall R (2003) Power to the patients. New Scientist, 40-43, 30 August 2003.

Bertolino A, Caforio G, Blasi G, De Candia M, Lattore V, Petruzzella V, Altamura M, Nappi G, Papa S, Callicott JH, et al. (2004) Interaction of COMT val 108/158 met genotype and olanzapine treatment on prefrontal cortical function in patients with schizophrenia. American Journal of Psychiatry 161, 1798-1805.

Borroni B, Agosti C, Archetti S, Costanzi C, Bonomi S, Ghianda D, Lenzi GL, Caimi L, Di Luca M \& Padovani A (2004) Catechol$\mathrm{O}$-methyltransferase gene polymorphism is associated with risk of psychosis in Alzheimer disease. Neuroscience Letters 370, 127-129.

Botez MI, Young SN, Bachevalier J \& Gautier S (1979) Folate deficiency and decreased 5-hydroxytryptamine synthesis in man. Nature 278, 182-183.

Bottiglieri T (2002) S-adenosyl-L-methionine (SAMe): from the bench to the bedside - molecular basis of a pleiotrophic molecule. American Journal of Clinical Nutrition 76, Suppl., $1151 \mathrm{~S}-1157 \mathrm{~S}$

Bottiglieri T, Laundy M, Crellin R, Toone BK, Carney MWP \& Reynolds EH (2000) Homocysteine, folate, methylation, and monoamine metabolism in depression. Journal of Neurology, Neurosurgery and Psychiatry 69, 228-232.

Brockington IF \& Meakin CJ (1994) Clinical clues to the aetiology of puerperal psychosis. Progress in Neuropsychopharmacology and Biological Psychiatry 18, 417-429.

Carboni G, Tueting P, Tremolizzo I, Sugaya I, Davis J, Costa E \& Guidotti A (2004) Enhanced dizocilpine efficacy in heterozygous reeler mice relates to GABA turnover downregulation. Neuropharmacology 46, 1070-1081.

Chagoya de Sanchez VC, Hernandez-Munoz R, Sanchez L, Vidrio S, Yanez L \& Suarez J (1991) Twenty-four hour changes of S-adenosylmethionine, S-adenosylhomocysteine adenosine and their metabolising enzymes in rat liver; possible physiological significance in phospholipid methylation. International Journal of Biochemistry 23, 1439-1443.

Chen Y, Sharma RP, Costa RH, Costa E \& Grayson DR (2002) On the epigenetic regulation of the human reelin. Nucleic Acids Research 30, 2930-2939.

Chiaie RD, Pancheri P \& Scapicchio P (2002) Efficacy and tolerability of oral and intramuscular S-adenosyl-L-methionine 1,4-butanedisulfonate (SAMe) in the treatment of major depression: comparison with imipramine in 2 multicenter studies. American Journal of Clinical Nutrition 76, Suppl., $1172 \mathrm{~S}-1176 \mathrm{~S}$

Christman JK, Sheikhnejad G, Dizik M, Abileah S \& Wainfan E (1993) Reversibility of changes in nucleic acid methylation and gene expression induced in rat liver by severe methyl deficiency. Carcinogenesis 14, 551-557.

Clarke S \& Banfield K (2001) S-adenosylmethionine-dependent methyltransferases. In Homocysteine in Health and Disease, pp. 63-78 [R Carmel and DW Jacobsen, editors]. Cambridge, UK: Cambridge University Press.

Cohen M, Dembling B \& Schorling J (2002) The association between schizophrenia and cancer: a population-based mortality study. Schizophrenia Research 57, 139-146.

Cook RJ (2001) Folate metabolism. In Homocysteine in Health and Disease, pp. 113-134 [R Carmel and DW Jacobsen, editors]. Cambridge, UK: Cambridge University Press.

Cooney CA, Dave AA \& Wolff GL (2002) Maternal methyl supplements in mice affect epigenetic variation and DNA methylation of offspring. Journal of Nutrition 132, 2393S-2400S

da Costa K-A, Badea M, Fischer LM \& Zeisel SH (2004) Elevated serum creatine phosphokinase in choline-deficient humans: mechanistic studies in $\mathrm{C} 2 \mathrm{C} 12$ mouse myoblasts. American Journal of Clinical Nutrition 80, 163-170.

Davis SR, Stacpoole PW, Williamson J, Kick LS, Quinlivan EP, Coats BS, Shane B, Bailey LB \& Gregory JF III (2004) Tracerderived total and folate-dependent homocysteine remethylation and synthesis rates in humans indicate that serine is the main one-carbon donor. American Journal of Physiology 286, E272-E279.

DeLong CJ, Hicks AM \& Cui Z (2002) Disruption of choline methyl group donation for phosphatidylethanolamine methylation in hepatocarcinoma cells. Journal of Biological Chemistry 19, $17217-17225$

DeLong CJ, Shen Y-J, Thomas MJ \& Ciu Z (1999) Molecular distinction of phosphatidylcholine synthesis between the CDPcholine pathway and phosphatidylethanolamine methylation pathway. Journal of Biological Chemistry 274, 29683-29688.

Deth RC, DuRand CJ, Sharma A \& Liu D (1996) Lymphocyte phospholipid methylation is altered in schizophrenia. Biological Psychiatry 39, 504.

Detich N, Bovenzi V \& Szyf M (2003) Valproate induces replication-independent active DNA demethylation. Journal of Biological Chemistry 278, 27586-27592.

Ding D \& Greenberg ML (2003) Lithium and valproate decrease the membrane phosphatidylinositol/phosphatidylcholine ratio. Molecular Microbiology 47, 373-381.

Do KQ, Trabesinger AH, Kirsten-Kruger M, Lauer CJ, Dydak U, Hell D, Holsboer F, Boesiger P \& Cuenod M (2000) Schizophrenia: glutathione deficit in cerebrospinal fluid and prefrontal cortex in vivo. European Journal of Neuroscience 12, $3721-3728$.

Doraiswamy M, Martin W, Metz A \& Deveaugh-Geiss J (1995) Psychosis in Parkinson's disease: diagnosis and treatment. Progress in Neuro-Psychopharmacology and Biological Psychiatry 19, 835-846. 
Drouva SV, Rerat E, Leblanc P, Laplante E \& Kordon C (1987) Variations of phospholipid methyltransferase(s) activity in the rat pituitary: estrous cycle and sex differences. Endocrinology 121, 569-574.

Durand C, Mary S, Brazo P \& Dollfus S (2003) Psychiatric manifestations of vitamin B12 deficiency: a case report. Encephale 29, 560-565.

Durand P, Prost M \& Blache D (1995) Pro-thrombic effects of a folic acid deficient diet in rat platelets and macrophages related to elevated homocysteine and decreased n-3 polyunsaturated fatty acids. Atherosclerosis 121, 231-243.

Ende G, Braus DF, Walter S, Weber-Fahr W \& Henn FA (2000) The hippocampus in patients treated with electroconvulsive therapy. Archives of General Psychiatry 57, 937-943.

Fan J-B, Zhang C-S, Gu N-F, Li X-W, Sun W-W, Wany H-Y, Geny G-Y, St Clair D \& Hee L (2005) Catechol-Omethyltransferase gene $\mathrm{Val} / \mathrm{Met}$ functional polymorphism and risk of schizophrenia: a large-scale association study plus metaanalysis. Biological Psychiatry 57, 139-144.

Fatemi SH, Stary JM, Earle JA, Araghi-Nikman M \& Eagan E (2005) GABAergic dysfunction in schizophrenia and mood disorders as reflected by decreased levels of glutamic acid decarboxylase 65 and $67 \mathrm{kDa}$ and reelin proteins in cerebellum. Schizophrenia Research 72, 109-122.

Fatemi SH, Stary JM, Halt AR \& Realmuto GR (2001) Dysregulation of reelin and $\mathrm{Bcl}-2$ proteins in autistic cerebellum. Journal of Autism and Developmental Disorders 31, 529-535.

Finnell RH, Spiegelstein O, Wlodarczyk B, Triplett A, Pogribny IP, Melnyk S \& James JS (2002) DNA methylation in FolBP1 knockout mice supplemented with folic acid during gestation. Journal of Nutrition 132, 2457S-2461S.

Fournier I, Ploye F, Cottet-Emard J-M, Brun J \& Claustrat B (2002) Folate deficiency alters melatonin secretion in rats. Journal of Nutrition 132, 2781-2784.

Fraga MF, Ballestar E, Paz MF, Ropero S, Setien F, Ballestar ML, Heine-Suner D, Cigudosa JC, Urioste M, Benitez J, et al. (2005) Epigenetic differences arise during the lifetime of monozygotic twins. Proceedings of the National Academy of Sciences USA 102, 10604-10609.

Glatt SJ, Faraone SV \& Tsuang MT (2003) Association between a functional catechol-O-methyltransferase gene polymorphism and schizophrenia: meta-analysis of case-control and familybased studies. American Journal of Psychiatry 160, 469-476.

Glen ACA, MacDonald DJ \& Boyle RM (2003a) Cytosolic phospholipase A2 (IVAPLA2) in red cells in schizophrenia and other psychiatric disorders. In Phospholipid Spectrum Disorders in Psychiatry, pp. 183-192 [M Peet, I Glen and DF Horrobin, editors]. Carnforth, Lancs, UK: Marius Press.

Glen I, McKenzie I, Obajimi K, Dodd GH, Ward PE \& Ross BM (2003b) Markers of oxidative damage in exhalant and their use in schizophrenia and other disorders. In Phospholipid Spectrum Disorders in Psychiatry, pp. 357-364 [M Peet, I Glen and DF Horrobin, editors]. Carnforth, Lancs, UK: Marius Press.

Gluckman P \& Hanson M (2005) The Fetal Matrix. Evolution, Development and Disease. Cambridge, UK: Cambridge University Press.

Godfrey PS, Toone BK, Carney MW, Flynn TG, Bottiglieri T, Laundy M, Chanarin I \& Reynolds EH (1990) Enhancement of recovery from psychiatric illness by methylfolate. Lancet 336, $392-395$.

Goff DC, Bottiglieri T, Arning E, Shih V, Freundenreich O, Evins AE, Henderson DC, Baer L \& Coyle J (2004) Folate, homocysteine and negative symptoms in schizophrenia. American Journal of Psychiatry 161, 1705-1708.

Grima G, Benz B, Parpura V, Cuenod M \& Do KQ (2003) Dopamine-induced oxidative stress in neurons with glutathione deficit: implication for schizophrenia. Schizophrenia Research 62, 213-224.

Grinshpoon A, Barchana M, Ponizovsky A, Lipshitz I, Nahon D, Tal O, Weizman A \& Levav I (2005) Cancer in schizophrenia: is the risk higher or lower? Schizophrenia Research 73, 333-341.

Guidotti A, Auta J, Davis JM, Di-Giorgi-Gerevini V, Dwivedi Y, Grayson DR, Impagnatiello F, Pandey G, Pesold C, Sharma R, et al. (2000) Decrease in reelin and glutamic acid decarboxylase $_{67}\left(\mathrm{GAD}_{67}\right)$ expression in schizophrenia and bipolar disorder. Archives of General Psychiatry 57, $1061-1069$

Gultepe M, Ozcan O, Avsar K, Cetin M, Ozdemir AS \& Gok M (2003) Urine methylmalonic acid measurements for the assessment of cobalamin deficiency related to neuropsychiatric disorders. Clinical Biochemistry 36, 275-282.

Heresco-Levy U, Javitt DC, Ermilov M, Mordel C, Silipo G \& Lichtenstein M (1999) Efficacy of high-dose glycine in the treatment of enduring negative symptoms of schizophrenia. Archives of General Psychiatry 56, 29-36.

Hermesh H, Manor I, Shiloh R, Weizman R \& Munitz H (2001) Absence of myoglobinuria in acute psychotic patients with marked elevation in serum creatine phosphokinase level. European Neuropsychopharmacology 11, 111-115.

Hirata F \& Axelrod J (1980) Phospholipid methylation and biological signal transmission. Science 209, 1082-1090.

Hoffer A, Osmond H \& Smythies JR (1954) Schizophrenia: a new approach. Part II. Journal of Mental Science 100, 29-45.

Hook EB \& Czeizel AE (1997) Can terathanasia explain the protective effect of folic-acid supplementation on birth defects? Lancet 350, 513-515.

Horrobin DF (1999) The phospholipid concept of psychiatric disorders and its relationship to the neurodevelopmental concept of schizophrenia. In Phospholipid Spectrum Disorder in Psychiatry, pp. 3-20 [M Peet, I Glen and DF Horrobin, editors]. Carnforth, Lancs, UK: Marius Press.

Hunter R, Barnes J, Oakeley HF \& Matthews DM (1970) Toxicity of folic acid given in pharmacological doses to healthy volunteers. Lancet i, 61-63.

Hustad S, Ueland PM, Vollset SE, Zhang Y, Bjorke-Monsen AL \& Schneede J (2000) Riboflavin as a determinant of plasma total homocysteine: effect modification by the methylenetetrahydrofolate reductase C677T polymorphism. Clinical Chemistry 46, 1065-1071.

Impagnatiello F, Guidotti A, Pesold C, Dwivedi Y, Caruncho H, Pisu MG, Uzunov DP, Smalheiser NR, Davis JM, Pandey GN, et al. (1998) A decrease of reelin expression as a putative vulnerability factor in schizophrenia. Proceedings of the National Academy of Sciences USA 95, 15718-15723.

Ingrosso D, Cimmino A, Perna AF, Masella L, De Santo NG, De Bonis ML, Vacca M, D’Esposito M, D’Urso M, Galletti P, et al. (2003) Folate treatment and unbalanced methylation and changes of allelic expression induced by hyperhomocysteinaemia in patients with uraemia. Lancet 361, 1693-1699.

James SJ, Cutler P, Melnyk S, Jernigan S, Janak L, Gaylor DE \& Neubrander JA (2004) Metabolic biomarkers of increased oxidative stress and impaired methylation capacity in children with autism. American Journal of Clinical Nutrition 80, 1611-1617.

Joober R, Benkelfat C, Lal S, Bloom D, Labelle A, Lalonde P, Turecki G, Rozen R \& Rouleau GA (2000) Association between the methylenetetrahydrofolate reductase $677 \mathrm{C}-\mathrm{T}$ missense mutation and schizophrenia. Molecular Psychiatry 5, 323-326.

Khan M, Evans D, Gunna V, Scheffer RE, Parikh VV \& Mahadik SP (2002) Reduced erythrocyte membrane essential fatty acids and increased lipid peroxides in schizophrenia at the never-medicated first-episode of psychosis and after years of 
treatment with antipsychotics. Schizophrenia Research $\mathbf{5 8}$ $1-10$.

Kim YI (2000) Methylenetetrahydrofolate reductase polymorphisms, folate, and cancer risk: a paradigm of gene-nutrient interactions in carcinogenesis. Nutrition Reviews 58, 205-209.

Kingsbury SJ \& Garver DL (1998) Lithium and psychosis revisited. Progress in Neuro-psychopharmacology and Biological Psychiatry 22, 249-263.

Levi RN \& Waxman S (1975) Schizophrenia, epilepsy, cancer, methionine, and folate metabolism. Pathogenesis of schizophrenia. Lancet ii, 11-13.

Levine J, Agam G, Sela BA, Garver DL, Torrey EF \& Belmaker RH (2005) CSF homocysteine is not elevated in schizophrenia. Journal of Neural Transmission 112, 297-302.

Levine J, Stahl Z, Sela BA, Gavendo S, Ruderman V \& Belmaker RH (2002) Elevated homocysteine levels in young male patients with schizophrenia. American Journal of Psychiatry 159, $1790-1792$.

Lewis SJ, Zammit S, Gunnell D \& Smith GD (2005) A metaanalysis of the MTHFR C677T polymorphism and schizophrenia risk. American Journal of Medical Genetics (Neuropsychiatric Genetics) 135B, 2-4.

Lindenbaum J, Healton EB \& Savage DG (1988) Neuropsychiatric disorders caused by cobalamin deficiency in the absence of anemia or macrocytosis. New England Journal of Medicine 318, $1720-1728$

Lipton SA, Kim W-K, Choi Y-B, Kumar S, D'Emilia DM, Rayudu PV, Arnelle DR \& Stamler JS (1997) Neurotoxicity associated with dual actions of homocysteine at the N-methyl-Daspartate receptor. Proceedings of the National Academy of Sciences USA 94, 5923-5928.

McGrath M, Kawachi I, Ascherio A, Colditz GA, Hunter DJ \& De Vivo I (2004) Association between catechol-O-methyltransferase and phobic anxiety. American Journal of Psychiatry 161, $1703-1705$.

Maclean R, Ward PE, Glen I, Roberts SJ \& Ross BM (2003) On the relationship between methylnicotinate-induced skin-flush and fatty acids levels in acute psychosis. Progress in Neuropsychopharmacology and Biological Psychiatry 27, 927-933.

McNulty H, McKinley M, Wilson B, McPartlin J, Strain JJ, Weir DG \& Scott JM (2002) Impaired functioning of thermolabile methylenetetrahydrofolate reductase is dependent on riboflavin status: implications for riboflavin requirements. American Journal of Clinical Nutrition 76, 436-441.

Manor I, Hermesh H, Valevski A, Benjamin Y, Munitz H \& Weizman A (1998) Recurrence pattern of serum creatine phosphokinase levels in repeated acute psychosis. Biological Psychiatry 43, 288-292.

Miller JW, Selhub J, Nadeau MR, Thomas CA, Feldman RG \& Wolf PA (2003) Effect of 1-dopa on plasma homocysteine in PD patients. Neurology 60, 1125-1129.

Mischoulon D \& Fava M (2002) Role of S-adenosyl-methionine in the treatment of depression: a review of the evidence. American Journal of Clinical Nutrition 76, Suppl., 1158S-1161S.

Molloy AM \& Weir DG (2001) Homocysteine and the nervous system. In Homocysteine in Health and Disease, pp. 183-198 [R Carmel and DW Jacobsen, editors]. Cambridge, UK: Cambridge University Press.

Muller T, Renger K \& Kuhn W (2004) Levodopa-associated increase of homocysteine levels and sural axonal neurodegeneration. Archives of Neurology 61, 657-660.

Munoz-Moran E, Dieguez-Lucena JL, Fernandez-Arcas N, PeranMesa S \& Reyes-Engel A (1998) Genetic selection and folate intake during pregnancy. Lancet 352, 1120-1121.

Muntjewerff J-W, van der Put N, Eskes T, Ellenbroek B, Steegers E, Blom H \& Zitman F (2003) Homocysteine metabolism and B-vitamins in schizophrenic patients: low plasma folate as a possible independent risk factor for schizophrenia. Psychiatry Research 121, 1-9.

Na C \& Lee YS (2004) Serum homocysteine, folate level and MTHFR 677, 1298 gene polymorphism in schizophrenia. European Neuropsychopharmacology 14, Suppl. 3, S232-S233.

Noh JS, Sharma RP, Veldic M, Salvacion AA, Jia X, Chen Y, Costa E, Guidotti A \& Grayson DR (2004) DNA methyltransferase 1 regulates reelin mRNA expression in mouse primary cortical cultures. Proceedings of the National Academy of Sciences USA 102, 1749-1754.

Noga AA, Stead LM, Zhao Y, Brosnan ME, Brosnan JT \& Vance DE (2003) Plasma homocysteine is regulated by phospholipid methylation. Journal of Biological Chemistry 278, 5952-5955.

Noga AA \& Vance DE (2003) A gender-specific role for phosphatidylethanolamine-N-methyltransferase-derived phosphatidylcholine in the regulation of plasma high density and very low density lipoproteins in mice. Journal of Biological Chemistry 278, 21851-21859.

Olney JW, Newcomer JW \& Farber NB (1999) NMDA receptor hypofunction model of schizophrenia. Journal of Psychiatric Research 33, 523-533.

Oltean S \& Banerjee R (2003) Nutritional modulation of gene expression and homocysteine utilisation by vitamin B12. Journal of Biological Chemistry 278, 20778-20784.

Osher Y, Sela B-A, Levine J \& Belmaker RH (2004) Elevated homocysteine levels in euthymic bipolar disorder patients showing functional deterioration. Bipolar Disorders 6, 82 .

Peet M \& Bennett CN (1999) Relationship between brain lipids, depression and suicide. In Phospholipid Spectrum Disorder in Psychiatry, pp. 403-408 [M Peet, I Glen and DF Horrobin, editors]. Carnforth, Lancs, UK: Marius Press.

Peet M, Brind J, Ramchand CN, Shah S \& Vankar GK (2000) Two double-blind placebo-controlled pilot studies of eicosapentanoic acid in the treatment of schizophrenia. Schizophrenia Research 49, 243-251.

Persico AM, D'Agruma L, Maiorano N, Totaro A, Militerni R, Bravaccio C, Wassink TH, Schneider C, Melmed R, Trillo S, et al. (2001) Reelin gene alleles and haplotypes as a factor predisposing to autistic disorder. Molecular Psychiatry 6, 150-159.

Petronis A, Gottesman II, Kan P, Kennedy JL, Basile VS, Paterson AD \& Popendikyte V (2003) Monozygotic twins exhibit numerous epigenetic differences: clues to twin discordance? Schizophrenia Bulletin 29, 169-178.

Petry CJ, Ozanne SE \& Hales CN (2001) Programming of intermediary metabolism. Molecular and Cellular Endocrinology 185, 81-91.

Quinlivan EP \& Gregory JF III (2003) Effect of food fortification on folic acid intake in the United States. American Journal of Clinical Nutrition 77, 221-225.

Rees WD, Hay SM, Brown DS, Antipatis C \& Palmer RM (2000) Maternal protein deficiency causes hypermethylation of DNA in the livers of rat fetuses. Journal of Nutrition 130, 1821-1826.

Regland B, Abrahamsson L, Blennow K, Grebfeldt B \& Gottfries CG (2004) CSF-methionine is elevated in psychotic patients. Journal of Neural Transmission 111, 631-640.

Reichelt KL, Hole K, Hamberger A, Saelid G, Edminson PD, Braestrup CB, Lingjaerde O, Ledaal P \& Orbeck H (1981) Biologically active peptide-containing fractions in schizophrenia and childhood autism. Advances in Biochemical Psychopharmacology 28, 627-643.

Reynolds EH (2002) Benefits and risks of folic acid to the nervous system. Journal of Neurology, Neurosurgery and Psychiatry 72, $567-571$.

Rogers JD, Sanchez-Saffron A, Frol AB \& Diaz-Arrastia R (2003) Elevated plasma homocysteine in patients treated with 
levodopa: association with vascular disease. Archives of Neurology 60, 59-64.

Rosa A, Peralta V, Cuesta MJ, Zarzuela A, Serrano F, Martinez-Larrea A \& Fananas L (2004) New evidence of association between COMT gene and prefrontal neurocognitive function in healthy individuals from sibling pairs discordant for psychosis. American Journal of Psychiatry 161, 1110-1112.

Ross BM, Hudson C, Erlich J, Warsh JJ \& Kish SJ (1997) Increased phospholipid breakdown in schizophrenia. Evidence for the involvement of calcium-independent phospholipase A2. Archives of General Psychiatry 54, 487-494.

Rowling MJ, McMullen MH, Chipman DC \& Schalinske KL (2002) Hepatic glycine N-methyltransferase is up-regulated by excess dietary methionine in rats. Journal of Nutrition 132, $2545-2550$.

Sargent T III, Kusubov N, Taylor SE \& Budinger TF (1992) Tracer kinetic evidence for abnormal methyl metabolism in schizophrenia. Biological Psychiatry 32, 1078-1090.

Sarmiento IA, Stoll AL \& Cohen B (1999) The role of essential lipids in the management of bipolar disorder. In Phospholipid Spectrum Disorder in Psychiatry, pp. 457-462 [M Peet, I Glen and DF Horrobin, editors]. Carnforth, Lancs, UK: Marius Press.

Sartorius A, Neumann-Haefelin C, Vollmayr B, Hoehn M \& Henn FA (2003) Choline rise in the rat hippocampus induced by electroconvulsive shock treatment. Biological Psychiatry 53, 620-623.

Sazci A, Ergul E, Guzelhan Y, Kaya G \& Kara I (2003) Methylenetetrahydrofolate reductase gene polymorphisms in patients with schizophrenia. Molecular Brain Research 117, 104-107.

Shumeiko O, Levine J, Sela BA \& Belmaker RH (2003) Homocysteine reducing strategies in chronic schizophrenic patients with hyperhomocysteinemia. European Journal of Neuropsychopharmacology 13, Suppl. 4, S280-S281.

Singh U, Yokota K, Gupta C \& Shinozuka H (1990) Choline deficiency activates phospholipases A2 and C in rat liver without affecting the activity of protein kinase C. Journal of Nutritional Biochemistry 1, 434-439.

Slack A, Cervoni N, Pinard M \& Schizophrenicyf M (1999) Feedback regulation of DNA methyltransferase gene expression by methylation. European Journal of Biochemistry 264, $191-199$.

Stahl Z, Belmaker RH, Friger M \& Levine J (2005) Nutritional and life style determinants of plasma homocysteine in schizophrenic patients. European Neuropsychopharmacology 15, 291-295.

Stead LM, Jacobs RL, Brosnan ME \& Brosnan JT (2004) Methylation demand and homocysteine metabolism. Advances in Enzyme Regulation 44, 321-333.

Susser E, Brown AS, Klonowski E, Allen RH \& Lindenbaum J (1998) Schizophrenia and impaired homocysteine metabolism: a possible association. Biological Psychiatry 44, 141-143.

Tiemeier H, Ruud van Tuijl H, Hofman A, Meijer J, Kilian AJ \& Breteler MMB (2002) Vitamin B12, folate, and homocysteine in depression: The Rotterdam Study. American Journal of Psychiatry 159, 2099-2101.

Tolbert LC, Monti JA, Walter-Ryan W, Alarcon RD, Bahar B, Keriotis JT, Allison JG, Cates A, Antun F \& Smythies JR (1988) Clinical correlations of one-carbon metabolism abnormalities. Progress in Neuropsychopharmacology and Biological Psychiatry 12, 491-502.

Tolmunen T, Hintikka J, Ruusunen A, Voutilainen S, Tanskanen A, Valkonen VP, Viinamaki H, Kaplan GA \& Salonen JT (2004) Dietary folate and the risk of depression in Finnish middle-aged men. A prospective follow-up study. Psychotherapy and Psychosomatics 73, 334-339.
Tolmunen T, Voutilainen S, Hintikka J, Rissanen T, Tanskanen A, Viinamaki H, Kaplan GA \& Salonen JT (2003) Dietary folate and depressive symptoms are associated in middle-aged Finnish men. Journal of Nutrition 133, 3233-3236.

Tremolizzo L, Carboni G, Ruzicka WB, Mitchell CP, Sugaya I, Tueting P, Sharma R, Grayson DR, Costa E \& Guidotti A (2002) An epigenetic mouse model for molecular and behavioural neuropathologies related to schizophrenia vulnerability. Proceedings of the National Academy of Sciences USA 99, 17095-17100.

Tremolizzo L, Doueiri M-S, Dong E, Grayson DR, Davis J, Pinna G, Tueting P, Rodriguez-Menendez V, Costa E \& Guidotti A (2005) Valproate corrects the schizophrenia-like epigenetic behavioural modifications induced by methionine in mice. Biological Psychiatry 57, 500-509.

Tsai G, Lane H-Y, Yang P, Chong M-Y \& Lange N (2004) Glycine transporter 1 inhibitor, N-methylglycine (sarcosine), added to antipsychotics for the treatment of schizophrenia. Biological Psychiatry 55, 452-456.

Tsai G, Tang P, Chung L-C, Lange N \& Coyle JT (1998) D-serine added to antipsychotics for the treatment of schizophrenia. Biological Psychiatry 44, 1081-1089.

Tuominen HJ, Tiihonen J \& Wahlbeck K (2005) Glutamatergic drugs for schizophrenia: a systematic review and meta-analysis. Schizophrenia Research 72, 225-234.

Ueland PM, Hustad S, Schneede J, Refsum H \& Vollset SE (2001) Biological and clinical implications of the MTHFR C677T polymorphism. Trends in Pharmacological Sciences 22, 195-201.

Vance DE, Walkey CJ \& Cui Z (1997) Phosphatidylethanolamine N-methyltransferase from liver. Biochimica et Biophysica Acta 1348, 142-150.

Veldic M, Caruncho HJ, Liu WS, Davis J, Satta R, Grayson DR, Guidotti A \& Costa E (2004a) DNA-methyltransferase 1 mRNA is selectively overexpressed in telencephalic GABAergic interneurons of schizophrenia brains. Proceedings of the National Academy of Sciences USA 101, 348-353.

Veldic M, Guidotti A, Maloku E, Davis JM \& Costa E (2004b) In psychosis, cortical interneurons overexpress DNA-methyltransferase 1. Proceedings of the National Academy of Sciences USA 102, 2152-2157.

Virgos C, Martorell L, Simo JM, Valero J, Figureuera L, Joven J, Labad A \& Vilella E (1999) Plasma homocysteine and the methylenetetrahydrofolate reductase C677T gene variant: lack of association with schizophrenia. Neuroreport 10, 2035-2038.

Waterland RA \& Jirtle RL (2003) Transposable elements: targets for early nutritional effects on epigenetic gene regulation. Molecular and Cellular Biology 23, 5293-5300.

Watkins SM, Zhu X \& Zeisel SH (2003) Phosphatidylethanolamine-N-methyltransferase activity and dietary choline regulate liver-plasma lipid flux and essential fatty acid metabolism in mice. Journal of Nutrition 133, 3386-3391.

Waziri R, Baruah S \& Sherman AD (1992) Abnormal serineglycine metabolism in the brains of schizophrenics. Schizophrenia Research 8, 233-243.

Waziri R \& Mott J (1986) Drug effects on serine metabolism in psychiatric patients. Psychiatry Research 18, 119-126.

Weaver ICG, Champagne FA, Brown SE, Dymov S, Sharma S, Meaney MJ \& Szyf M (2005) Reversal of maternal programming of stress responses in adult offspring through methyl supplementation: altering epigenetic marking later in life. Journal of Neuroscience 25, 11045-11054.

Weickert TW, Goldberg TE, Mishara A, Apud JA, Kolachana BS, Egan MF \& Weinberger DR (2004) Catechol-O-methyltransferase Val108/158Met genotype predicts working memory response to antipsychotic medications. Biological Psychiatry 56, 677-682. 
Weir DG \& Molloy AM (2000) Microvascular disease and dementia in the elderly: are they related to hyperhomocysteinemia? American Journal of Clinical Nutrition 71, 859-860.

Weir DG \& Scott JM (1995) The biochemical basis of the neuropathy in cobalamin deficiency. Bailliere's Clinical Haematology 8, 479-497.

Weisberg I, Tran P, Christensen B, Sibani S \& Rozen R (1998) A second genetic polymorphism in methylenetetrahydrofolate reductase (MTHFR) associated with decreased enzyme activity. Molecular Genetics and Metabolism 64, 169-172.
Wyatt RJ, Termini BA \& Davis J (1971) Biochemical and sleep studies of schizophrenia: a review of the literature - 19601970. Schizophrenia Bulletin 4, 10-44.

Zeisel SH, Mar M-H, Howe JC \& Holden JM (2003) Concentrations of choline-containing compounds and betaine in common foods. Journal of Nutrition 133, 1302-1307.

Zhao R, Chen Y, Tan W, Waly M, Sharma A, Stover P, Rosowsky A, Malewicz B \& Deth RC (2001) Relationship between dopamine-stimulated phospholipid methylation and the singlecarbon folate pathway. Journal of Neurochemistry 78, 788-796. 